NBER WORKING PAPER SERIES

\title{
STATISTICAL DISCRIMINATION AND DURATION DEPENDENCE IN THE JOB FINDING RATE
}

\author{
Gregor Jarosch \\ Laura Pilossoph \\ Working Paper 24200 \\ http://www.nber.org/papers/w24200 \\ NATIONAL BUREAU OF ECONOMIC RESEARCH \\ 1050 Massachusetts Avenue \\ Cambridge, MA 02138 \\ January 2018
}

We thank Sushant Acharya, Adrien Auclert, Steven Davis, Peter Diamond, Michael Elsby, Loukas Karabarbounis, Fabian Lange, Matthew Notowidigdo, Richard Rogerson, Robert Shimer, Isaac Sorkin, Shu Lin Wee, and the audiences at various seminars and conferences for their thoughts and comments. The views expressed herein are those of the authors and do not necessarily reflect the views of the National Bureau of Economic Research.

NBER working papers are circulated for discussion and comment purposes. They have not been peer-reviewed or been subject to the review by the NBER Board of Directors that accompanies official NBER publications.

(C) 2018 by Gregor Jarosch and Laura Pilossoph. All rights reserved. Short sections of text, not to exceed two paragraphs, may be quoted without explicit permission provided that full credit, including $(\odot$ notice, is given to the source. 
Statistical Discrimination and Duration Dependence in the Job Finding Rate

Gregor Jarosch and Laura Pilossoph

NBER Working Paper No. 24200

January 2018

JEL No. E24,J64

\begin{abstract}
$\underline{\text { ABSTRACT }}$
This paper models a frictional labor market where employers endogenously discriminate against the long term unemployed. The estimated model replicates recent experimental evidence which documents that interview invitations for observationally equivalent workers fall sharply as unemployment duration progresses. We use the model to quantitatively assess the consequences of such employer behavior for job finding rates and long term unemployment and find only modest effects given the large decline in callbacks. Interviews lost to duration impact individual job-finding rates solely if they would have led to jobs. We show that such instances are rare when firms discriminate in anticipation of an ultimately unsuccessful application. Discrimination in callbacks is thus largely a response to dynamic selection, with limited consequences for structural duration dependence and long term unemployment.
\end{abstract}

\author{
Gregor Jarosch \\ Department of Economics \\ Princeton University \\ 195 Julis Rabinowitz Building \\ Princeton, NJ 08544 \\ and NBER \\ gregorjarosch@gmail.com \\ Laura Pilossoph \\ Macroeconomics and Monetary Studies Function \\ Federal Reserve Bank of New York \\ 33 Liberty Street \\ New York, NY 10045 \\ pilossoph@gmail.com
}




\section{Introduction}

Recent experimental work shows that employers are reluctant to interview long term unemployed workers. For example, using a large-scale resume audit study, Kroft et al. (2013) document that callback rates in response to job applications decline substantially with unemployment duration. All else equal, they find that a worker unemployed for 8 months is 45 percent less likely to receive a callback for an interview than an observationally equivalent newly unemployed worker. Farber et al. (2016), Eriksson and Rooth (2014), Ghayad (2013), and Oberholzer-Gee (2008) also study, via the same experimental approach, how unemployment duration affects a worker's chances of receiving an interview.

In this paper, we develop a tractable model of the hiring process to quantify the consequences of such employer behavior for job finding rates and long term unemployment. We do so motivated by the simple observation that not all interviews lost to unemployment duration translate into lost jobs. That is, discrimination against unemployment duration matters for employment outcomes to the extent that it alters who receives and who is denied a job. Therefore, quantifying the implications of the experimental evidence for the labor market requires taking a stance on the details of the interviewing and hiring process. ${ }^{1}$

To this end, we model a frictional labor market with a two-stage hiring process which lends itself tightly to the experimental evidence, connecting callbacks with job finding rates. Firms receive applications from workers who differ in ways that matter to employers, yet are unobservable on a resume. They then decide on whether or not to follow up with an interview. If they do so, they call back the worker for a costly interview in which they can learn more about the applicant. Because more qualified workers are more likely to get hired upon completing an interview, low ability workers are more likely to be long term unemployed and duration contains information about a worker's ability. ${ }^{2}$ As a result, employers react to this information by conditioning their callback decisions on unemployment duration; they statistically discriminate against workers with higher unemployment duration. ${ }^{3}$

The two key metrics we use to gauge the impact of discrimination on the labor market

\footnotetext{
${ }^{1}$ Eriksson and Rooth (2014) describe that, "a limitation of [the field experiment] approach is that [it] studie[s] only the early stages of the hiring process since we do not know whom the employers eventually decide to hire." Similarly, Kroft et al. (2013) recognize that their field experiment "can only shed light on negative duration dependence in callback rates." See Heckman (1998) for similar arguments.

${ }^{2}$ This selection into long term unemployment is known as dynamic selection.

${ }^{3}$ We note that discrimination may well extend into later stages of the hiring process. However, our focus is on discrimination at the callback stage since this is the focus of the experimental literature. Thus, throughout the paper, we use the term discrimination in reference to discrimination against unemployment duration at the interview or callback stage.
} 
are (i) the incidence of long term unemployment and (ii) structural duration dependence in the job finding rate generated by discrimination. The former is simply the fraction of the population which is unemployed for more than 6 months. The latter, sometimes referred to as "true" duration dependence, is the component of duration dependence in the job finding rate which is a direct consequence of duration and not driven simply by composition changes- the fact that types with lower exit rates stay unemployed longer, mechanically lowering the average job finding rate as duration increases.

To quantify those metrics we estimate our framework, targeting the decline in average job finding rates in the Current Population Survey (CPS) as well as the duration dependence in callbacks identified in Kroft et al. (2013). Our framework gives rise to an exact counterpart to the experimental evidence, namely a callback rate for interviews that may vary with the unemployment rate. ${ }^{4}$

We show that the estimated model economy closely captures our empirical targets. We reproduce how the empirical exit rate from unemployment varies with unemployment duration. More importantly, the model closely replicates the experimentally measured decay in the interview rate. That is, if one were to conduct a resume audit study in our model economy, one would detect the same degree of discrimination as found in Kroft et al. (2013).

We further show that firms discriminate substantially less in our model if the labor market has slack because dynamic selection weakens when workers meet firms less frequently, quantitatively consistent with evidence in Kroft et al. (2013). A model of tastebased discrimination, such as Blanchard and Diamond (1994), cannot immediately account for this fact. ${ }^{5}$

In line with the evidence, the model generates a rapid and large decline in the interview rate with unemployment duration: long term unemployed workers receive around $50 \%$ less interviews compared to a newly unemployed worker with an equivalent resume. Given the size of these effects, one may thus suspect, prima facie, that discrimination in

\footnotetext{
${ }^{4}$ Most other models of employer discrimination feature discrimination at the hiring stage. For example, Vishwanath (1989) and Lockwood (1991) study stylized models in which employers endogenously interpret the results of a test or signal in light of an applicant's unemployment duration. Hiring is conditioned on the result of the test and in the equilibrium with testing all firms interview their applicants. Doppelt (2016) studies the impact of unemployment stigma generated by a worker's entire labor market history on labor market outcomes. Job interviews get interpreted in light of such stigma, but are always conducted. In Fernandez-Blanco and Preugschat (2017), firms interview multiple applicants for suitability and endogenously hire the suitable candidate with the lowest duration.

${ }^{5}$ In Blanchard and Diamond (1994) firms rank applicants according to unemployment duration without having any reason to do so. In Coate and Loury (1993), discrimination is a feature of an equilibrium where employer beliefs are self-fulfilled through worker investment behavior. In a setup like ours, where the underlying dynamic selection that leads to group differences is mechanical, there is no equilibrium in which firms do not discriminate under plausible assumptions on the production technology spelled out below.
} 
callbacks is an important contributor to structural duration dependence in the job finding rate and the incidence of long term unemployment. ${ }^{6}$

However, our findings suggest that the impact of discrimination on our key metrics is very moderate. In a first exercise, we contrast the labor market in our equilibrium with a counterfactual that eliminates all discrimination. We show that, while the medium and long term unemployed receive almost twice as many interviews in the counterfactual, their job finding rate increases by a mere 3\%. This suggests a limited role of employer discrimination as a driver of structural duration dependence in the job finding rate. As a consequence, we find that eliminating all discrimination leads to a modest decline in the incidence of long term unemployment of less than $8 \%$.

Our second exercise directly decomposes duration dependence in the job finding rate into a compositional and structural component, the latter fully driven by statistical discrimination. Our results complement the findings from the counterfactual analysis: The bulk of the decline in the job finding rate is purely compositional, with the structural component accounting for less than $10 \%$ of the observed decline at all durations.

The reason behind these findings is that the share of false negatives-incidents in which firms deny interviews to workers who would have otherwise been hired-is low and thus few of the interviews lost to discrimination would have led to jobs. Therefore, our findings suggest that statistical discrimination is largely a response to compositional changes rather than an important driver of structural duration dependence and long term unemployment.

We use the simplicity of our baseline setup to provide a theoretically guided explanation for this result and show that firms, when making a callback decision, compare two key objects: The cost of calling back a worker who ultimately turns out to be a bad match, and the benefits of locating a suitable candidate. The reason false negatives are rare is then that the benefits of forming a viable employment relationship far exceed the cost of an interview. In this case, firms only discriminate, passing on interview opportunities, when they are fairly certain those interviews will not turn into hires. This in turn implies that few of the interviews lost to duration are lost jobs. ${ }^{7}$

\footnotetext{
${ }^{6}$ Examples of work making such a connection in a quantitative fashion include Altonji et al. (2016), Bos et al. (2016), Sharone et al. (2015), and Torgovitsky (2016). Others that equate a lost interview (as detected by an audit study) with a lost job include Barnichon and Figura (2015), Haltiwanger et al. (2015), and Kekre (2017). Similarly, various policy items, such as the presidential memorandum in White-House (2014b), the US Department of Labor USDOL (2014), and anti-discrimination measures that were implemented at the state level in New York (Law-2013-014 (2013)), New Jersey (Public-Law-2011 (2011)), Oregon (Senate-Bill-1548 (2012)), and Washington D.C. (Code-32-162 (2012)) reference the audit study evidence at multiple occasions to motivate policy interventions aimed at battling the "negative cycle of long term unemployment" (WhiteHouse (2014a)).

${ }^{7}$ With this tradeoff in mind, we choose a deliberately conservative empirical strategy with regard to the
} 
While highly qualified workers are sharply affected by the decline in callbacks at longer unemployment durations, they usually exit unemployment quickly - which is precisely the reason some firms abstain from interviewing those with high duration. Nevertheless, we stress that our aggregate results mask considerable heterogeneity in the impact of discrimination: High types which "fall through the cracks" and become long term unemployed suffer from a large decline in their chances to escape unemployment because of the decline in callbacks they experience.

The final section of the paper extends our basic environment to allow for coordination frictions in the search process and human capital decay during non-employment. Both features have the potential to amplify the consequences of discrimination. First, multiple workers may apply for the same job; if firms rank applicants according to unemployment duration, those with high duration are crowded out by other applicants. And second, workers who experience a rejection at the interview stage may subsequently loose skill, further hampering their job finding rate.

We re-estimate this richer environment and rely on the same metrics to assess the impact of the decline in callbacks. Absent any discrimination, monthly job finding rates rise by $8 \%$ at some durations; these changes accumulate and lower the incidence of long term unemployment by around $20 \%$, in line with the notion that the added components amplify the results. Nevertheless, this impact is surprisingly small if one considers that eliminating discrimination almost doubles the monthly interview rate for the medium and long term unemployed. That is, the medium and long term unemployed experience an increase in monthly callbacks between $50 \%$ and $100 \%$, yet their job finding rate increases by an order of magnitude less. This again reflects that most of the additional interviews fail to convert into jobs. These results confirm the basic findings from the baseline setup and highlight the importance of guiding the quantitative inference from the purely experimental evidence to actual labor outcomes with a theory of the hiring process.

Our model-based approach can be viewed as an alternative to the statistical approaches taken in the micro-empirical literature that attempt to separately identify structural duration dependence from dynamic selection (e.g. Heckman and Singer (1984) and Van den Berg (2001)). More recently, Alvarez et al. (2016) revived this strand of work by showing how one can use information on workers with multiple non-employment spells to sort out structural duration dependence in the job finding rate from composition dynamics. They find little evidence for a structural decline in the job finding rate during the first year

objects determining these objects. We discuss this in detail in the empirical section. 
of unemployment. ${ }^{8}$ The key difference between our paper and this body of work is that it lumps all potential mechanisms generating structural duration dependence whereas ours aims at isolating the quantitative contribution of discrimination. ${ }^{9}$

More broadly, our results offer an important qualification for the audit-study approach to the labor market. Insofar as the observable the experimenter varies-in our case unemployment duration-is correlated with unobservables that matter for employers' hiring decisions, the strength of the connection between documented callbacks and job finding rates is not clear. We thus view modeling discrimination as an endogenous outcome-with a quantitative theory that is disciplined by the experimental evidence-as a promising way to conceptualize and quantify the causal impact of discrimination on labor market outcomes of interest. ${ }^{10}$

The paper proceeds as follows. The next section introduces the model. In Section 3 , we estimate the model using indirect inference. In Section 4 we use the estimated model to quantify the effects of discrimination structural duration dependence and long term unemployment. In section 5, we present the analysis of the extended model before concluding in section 6.

\section{Model}

\subsection{Environment}

We next introduce a simple search and matching model of the labor market that endogenously gives rise to employer discrimination.

Time is discrete and runs forever. All agents discount the future at rate $\beta$, have linear preferences, and produce and consume a single homogeneous good. There is a unit mass of infinitely lived workers indexed by their time-invariant type $x \in X=(\underline{x}, \bar{x}) .{ }^{11}$ The exogenous and time-invariant distribution of worker types is given by $l(x)$. For conve-

\footnotetext{
${ }^{8}$ For similar results, see Ahn and Hamilton (2017).

${ }^{9}$ In our baseline environment, the sole driver of structural duration dependence is statistical discrimination. There are many candidate drivers of structural duration dependence in job finding rates such as skill loss or stock flow matching, but we are interested in quantifying the impact of one particular driver, namely discrimination in callbacks. We allow for an interaction between discrimination and skill loss in the extended environment.

${ }^{10}$ We believe that modeling employer discrimination as entirely statistical—as opposed to taste based-is warranted in our setting. A similar approach could be used to analyze the evidence on discrimination in callbacks based on other observables. In such settings, modeling taste-biases is likely more important.

${ }^{11}$ When we use the model for quantitative purposes we also study an extension of this basic framework. In the extension we let workers' human capital depreciate during times of non-employment, relaxing the assumption of time-invariant types $x$.
} 
nience, we assume full support on $X$. Workers are either employed or unemployed with current duration $\tau \in[0,1,2, ..) .{ }^{12}$ Unemployed workers receive flow utility $b$ per period.

Production On the other side of the labor market is a continuum of heterogeneous firms indexed by their type $y \in Y=(y, \bar{y})$. The output of a firm-worker match is governed by the firm's type $y$ and the worker's type $x, p(x, y)$. We make two assumptions on the production function. First we assume that $p(x, y)$ is nondecreasing in $x$, and second, we assume that for all firms $y$ there exists a finite $\underline{x}_{y}$ such that

$$
\begin{array}{ll}
p(x, y) \geq b & \text { if } x \geq \underline{x}_{y} \\
p(x, y)<b & \text { otherwise. }
\end{array}
$$

Thus, there are firm-specific minimum skill requirements. If a worker fails to satisfy firm $y$ 's skill requirement $\underline{x}_{y}$ the pair cannot produce enough output to cover the flow value of unemployment. $^{13}$

These assumptions are at the core of our setup and will generate two important implications: First, higher worker types $x$ will exit unemployment faster since they have positive (net) output with a larger fraction of firms $y$. Second, a larger fraction of firms $y$ will follow up on an application if the worker behind that application is likely to have high $x .^{14}$

The Hiring Process At any point in time, unemployed workers face an exogenous distribution of job openings $F(y)$ with full support on $Y$. Workers are unemployed because the process that pairs them with job openings is subject to search frictions. Specifically, search is random and an unemployed worker's resume makes contact with a vacancy at an exogenous rate $\lambda .{ }^{15}$ Upon receiving a resume, firms cannot observe the worker's type $x$, but can readily observe the worker's current unemployment duration $\tau .^{16}$ The firm can then follow up on the application by calling back the worker and inviting her for an

\footnotetext{
${ }^{12}$ Throughout, we adopt the convention that $\tau=0$ corresponds to the first period of unemployment, such that $\tau=t$ corresponds to those with unemployment duration between $t$ and $t+1$ periods.

${ }^{13}$ We further discuss the production function and its empirical relevance in the quantitative section where we impose additional structure.

${ }^{14}$ These implications of the production function are subject to an assumption on wage setting which we introduce and discuss below.

${ }^{15}$ Here, we assume one-on-one matching where firms consider applications in isolation. This is the second key assumption we relax in the extension studied below: There, we allow for coordination frictions where multiple workers might apply to the same job.

${ }^{16}$ As in Arrow (1973), let $x$ thus capture "more subtle types of personal deprivation and deferment of gratification which lead to the habits and action of thought that favor good performance in skilled jobs, steadiness, punctuality, responsiveness, and initiative."
} 
interview which costs the firm $\kappa$. The interview fully reveals the worker's type $x$. We denote by $I(\tau)$ the set of firms $y$ that interview workers with duration $\tau$. Since the interview is costly, firms may want to condition their callback decision on the available information $\tau$. We assume that the only information on a resume potentially relevant to an employer is current unemployment duration $\tau .{ }^{17}$

In light of the interview, the firm then decides whether or not to consummate the match. We denote by $H(x, \tau)$ the set of firms willing to hire a worker with current unemployment duration $\tau$ after having observed her type $x$.

Finally, firms and workers separate at exogenous rate $\delta_{H}$. In this case, the void job simply disappears. For the worker, we distinguish between two separate events. In the first, the worker becomes unemployed, occurring at rate $\delta_{L}<\delta_{H}$. In the second event, occurring at rate $\delta_{H}-\delta_{L}$, she exogenously transitions to another, identical employer. Jointly, these assumptions allow us to accommodate a high rate of job separation from the perspective of an employer without explicitly modeling on-the-job search or inflating the unemployment rate. ${ }^{18}$

\subsection{Workers}

Denote by $U(x, \tau)$ the value of being unemployed to a worker of type $x$ with current duration $\tau$. Denote by $W(x, y, \tau)$ the value of a job to a type $x$ worker who exited unemployment after $\tau$ periods and is currently employed at firm $y$. We can write the value of unemployment as

$$
U(x, \tau)=b+\beta\left(U(x, \tau+1)+\lambda \int_{y \in I(\tau) \cap H(x, \tau)}(W(x, y, \tau)-U(x, \tau+1)) d F(y)\right) .
$$

A worker exits unemployment if she contacts a firm that is both willing to grant her an interview and hire her. Otherwise, she remains unemployed with her duration increasing to $\tau+1$.

Employed workers receive a wage $w(x, y, \tau)$ which may generally depend upon their

\footnotetext{
${ }^{17}$ This assumption allows our framework to directly connect with the resume audit studies which isolate the role of current unemployment duration by orthogonalizing all other information on the fictitious resumes.

${ }^{18}$ As we describe below, this allows us to pursue a conservative empirical strategy with respect to the consequences of discrimination in a simple and tractable fashion.
} 
spell length when exiting unemployment. Thus,

$$
W(x, y, \tau)=w(x, y, \tau)+\beta\left(\left(1-\delta_{L}\right) W(x, y, \tau)+\delta_{L} U(x, 0)\right)
$$

which reflects that the worker becomes newly unemployed at exogenous rate $\delta_{L}$.

\subsubsection{Wage Setting}

We assume throughout that wages are Nash-bargained and fixed for the duration of a match. We further assume that firms have all the bargaining power. The worker's value functions and wages are then independent of unemployment duration $\tau$ and employer type $y, U(x, \tau)=U=W(x, y, \tau)=W=\frac{b}{1-\beta}$, where $w(x, y, \tau)=b \forall x, y, \tau .{ }^{19}$

While this assumption enormously simplifies the solution of the model, the implied degenerate wage distribution is, of course, empirically implausible which warrants some discussion. With respect to the objectives of this paper the assumption matters for two reasons. First, the assumption importantly implies that workers in our framework cannot escape a potential "unemployment trap" by reducing their reservation wages. However, we argue that there is scant empirical evidence suggesting that this is indeed a first-order driving force of the data. ${ }^{20}$ Furthermore, we highlight that allowing for such a margin would lead us to find a smaller impact of discrimination on labor market flows since those workers who would fear adverse consequences could avoid them through reduced reservation wages.

Second, and more importantly, the assumption also inflates the value of a filled job to a firm, since employers extract all the surplus. As we discuss in detail below (Section 4.3), the value of the filled job to the firm relative to interview costs is critical for our quantitative findings. Clearly, the value of the job to the firm depends not only on the bargaining power of the firm, but also on the flow value of unemployment $b$ since $w=b$ in all matches. We are hence careful to choose a value of $b$ high enough such that the value of a filled job to an employer connects closely to standard values in the literature, despite giving firms all the bargaining power. We thus argue that the assumption on wages, properly adjusted for in the calibration of the joint surplus through the choice of $b$, is innocuous for the consequences of discrimination for the job finding rate which is the focus of our analysis.

\footnotetext{
${ }^{19}$ This can readily be verified using equations (2) and (3). Once firms receive the full net surplus in any employment relationship the wage becomes independent of the worker's ability to find another job.

${ }^{20}$ Using longitudinal panel data on unemployed workers in New Jersey, Krueger and Mueller (2016) show that reservation wages decline, if at all, only modestly over an unemployment spell.
} 


\subsection{Firms - Interviewing and Hiring}

Let $J(x, y)$ denote the value a type-y employer derives from hiring a worker of type $x$. Since firms hold workers to their outside option, this is simply given by the present value of (net) output,

$$
J(x, y)=\frac{p(x, y)-b}{1-\beta\left(1-\delta_{H}\right)} .
$$

We note that $\delta_{H}$ is the rate at which the match separates from the perspective of the employer.

After a firm has interviewed a worker and learned about $x$, it decides whether or not to hire the worker. We assume that an unfilled vacancy has no continuation value. As a consequence, a vacancy that meets a worker will never be held open due to option value considerations. It follows that the set of firms willing to hire a worker of type $x$ is such that

$$
y \in H(x) \text { iff } p(x, y) \geq b .
$$

where the hiring set $H(\cdot)$ no longer depends on duration due to the wage setting assumption.

The joint distribution of unemployed workers of skill $x$ and duration $\tau$ depends on the hiring and interview decisions of firms. Taking into account the relationship between duration and skill, firms form expectations about $x$, conditional on a worker's unemployment duration $\tau$. Denote by $\mu(x \mid \tau)$ the conditional density of types $x$ at duration $\tau$. The set of firms following up on an application by a worker with current unemployment duration $\tau$ can be characterized as follows:

$$
y \in I(\tau) \text { iff } \int \max \{J(x, y), 0\} \mu(x \mid \tau) d x \geq \kappa
$$

The firm calls back if the expected value of doing so covers the interview cost $\kappa^{21}$ Otherwise the firm simply discards the application. Then, the pace at which the set $I(\tau)$ shrinks as duration progresses will determine the slope of the model-generated callback rate.

The next assumption on the distribution of firm types will guarantee that the set $I(\tau)$ indeed shrinks with duration. First, we assume that for all firms $y \in Y$

\footnotetext{
${ }^{21}$ In general, there might be cases where it is optimal for firms to skip the interview and hire the worker directly. We rule this out by assumption. To micro-found this, one can assume the existence of a zero measure of agents that cause employers losses sufficiently large for them to avoid hiring an unscreened worker.
} 


$$
\int \max \{J(x, y), 0\} l(x) d x>\kappa
$$

In words, all firms find it worthwhile interviewing when faced with the population distribution of workers. Next, we assume that firms with $y$ such that

$$
J(\underline{x}, y)<\kappa
$$

account for a strictly positive fraction of vacancies. That is, there exist some job openings which do not follow up on an application if they are certain that it is associated with a worker of the lowest type. These two assumptions are sufficient to rule out cases where either no firm interviews and the economy has no employment, and cases where all firms always interview, irrespective of duration.

We highlight that, just like in the experimental settings, job applicants are observationally equivalent and differ only in their current unemployment duration $\tau$. Yet hiring decisions depend on worker characteristics beyond what is recognizable on a resume. It follows that the pool of unemployed workers changes its composition along dimensions relevant to employers as duration progresses and firms project these dynamics on $\tau$; there is information inherent in $\tau$ which firms naturally use in the hiring process. Thus, any interpretation of the experimental evidence on the basis of an all-else-equal notion fails to recognize the very process that gives rise to declining callbacks in the first place.

\subsection{Steady State Stocks}

To compute the conditional density $\mu(x \mid \tau)$ firms need to know the distribution of $x$ among the unemployed. To characterize the latter, denote by $e(x)$ the employment rate of type $x$ workers. In turn, denote by $u(x, \tau)$ the fraction of type $x$ workers unemployed with duration $\tau$ such that $\sum_{\tau=0}^{\infty} u(x, \tau)$ is the unemployment rate among type $x$ workers. In steady state, $u(x, \tau)$ satisfies

$$
u(x, \tau)= \begin{cases}\delta_{L} e(x) & \text { if } \tau=0 \\ u(x, \tau-1)\left(1-\lambda \int_{y \in I(\tau-1) \cap H(x)} d F(y)\right) & \text { if } \tau>0 .\end{cases}
$$

Employed workers become unemployed with duration $\tau=0$ at rate $\delta_{L}$. The unemployed who do not find work increase their duration by one period. In turn, the fraction of employed workers of type $x$ is given by the sum of non-separating incumbents and those 
newly hired from unemployment,

$$
e(x)=\left(1-\delta_{L}\right) e(x)+\lambda \sum_{\tau=0}^{\infty} u(x, \tau) \int_{I(\tau) \cap H(x)} d F(y) .
$$

Finally, to pin the levels, $u(x, \tau)$ and $e(x)$ have to satisfy the adding up constraint

$$
e(x)=1-\sum_{\tau=0}^{\infty} u(x, \tau)
$$

\subsection{Equilibrium}

A steady state equilibrium of this economy is a triple $\{H, I, u\}$ where the hiring set $H$ satisfies (5), the interview set $I$ satisfies (6), and the allocation satisfies (9)-(11).

\subsection{Characterization}

To formally characterize the key features of equilibrium we begin by defining discrimination.

Definition 1. The equilibrium features discrimination against unemployment duration iff $I(\tau+1) \subseteq I(\tau)$ for all unemployment durations $\tau \geq 0$ and there exists a $\tau^{\star} \geq 0$ such that $I\left(\tau^{\star}+1\right) \subset I\left(\tau^{\star}\right)$.

In words, an equilibrium with discrimination is one where the callback rate as measured through the lens of an audit study never increases with duration and strictly declines sooner or later. ${ }^{22}$

We next formally characterize the equilibrium.

Proposition 1. The hiring decision for a firm $y$ is a cutoff rule in which it hires only workers whose type $x$ exceeds a firm-specific skill threshold. Firms use cutoff strategies for interviews, interviewing only workers whose unemployment duration falls below a firm-specific threshold. The equilibrium exhibits discrimination.

Proof. See Appendix.

Our framework gives rise to discrimination against unemployment duration as a simple consequence of dynamic selection. Given our assumptions on production, higher

\footnotetext{
${ }^{22}$ This definition allows for cases where all firms interview workers up to a duration threshold where some firms no longer call back.
} 
types $x$ are more desirable to a larger fraction of employers. ${ }^{23}$ Coupled with the assumption on wage setting, this implies that they also exit unemployment more quickly, giving rise to dynamic selection on unobservables as unemployment duration progresses. As a consequence, the fraction of employers following up on an application declines with unemployment duration and the economy features discrimination.

\section{The Consequences of Discrimination}

An immediate corollary of Proposition 1 is that the job finding rate, for a given type $x$, follows a similar pattern as the callback rate: It never increases with unemployment duration and it may fall in cases where a firm with skill requirement $\underline{x}_{y} \leq x$ ceases to call back.

More formally, to map the hiring practice characterized in Proposition 1 into its consequences for the job finding rate, it is important to note that for a worker $(x, \tau)$ to exit unemployment she needs to meet a firm $y$ which is both in her interview set $I(\tau)$ and in her hiring set $H(x)$. As an unemployed worker's duration increases she receives fewer interviews since firms discriminate. A key observation is that a worker $x$ experiences a decline in her chances of finding a job between $\tau$ and $\tau+1$ only if the firms that withdraw from interviewing are in her hiring set. The share of firms $y \in I(\tau) \cap I(\tau+1)^{c}$ constitutes the decline in the callback rate between $\tau$ and $\tau+1$. The share of firms $y \in I(\tau) \cap I(\tau+1)^{c} \cap H(x)$ constitutes the associated decline in the job finding rate for a worker of type $x$. This implies that some workers may not actually experience any decline in their job finding rate between $\tau$ and $\tau+1$, despite receiving fewer callbacks. At the same time, workers who are qualified for jobs that discriminate in callbacks will indeed experience a decline in their job finding rates.

In sum, interviews lost to discrimination reduce the job finding rate, but only if they would have led to jobs. Only false negatives - cases where a firm does not call back a worker who happens to be qualified for the job - will impact individual job finding rates. All other lost interviews simply move the timing of rejection from after the interview has been conducted to the callback stage. Thus, the remainder of the paper is an effort to quantify the frequency at which the refusal of firms to interview workers beyond some unemployment duration indeed constitutes a false negative.

\footnotetext{
${ }^{23}$ As we discuss below, Lise and Robin (2017) offer recent evidence in support of the assumption that the set of feasible matches is smaller for low-productivity types.
} 


\section{Estimation}

For the quantitative section, we modify Albrecht and Vroman (2002) and specify a production function that takes the following form:

$$
p(x, y)= \begin{cases}x+y, & \text { if } x \geq y \\ 0, & \text { otherwise }\end{cases}
$$

Beyond satisfying our assumptions on production, this particular functional form ensures that the model generates positive assortative matching since it is the highly productive firms which are the most selective. It also has the appealing interpretation that a worker is qualified for a job if $x \geq y$ and allows for a very clean mapping of discrimination into the job finding rate: Discrimination in callbacks affects a worker's job finding rate if and only if it comes from jobs she is qualified for. ${ }^{24}$ Further, the production function implies that, absent discrimination, a worker's job finding rate is given by $F(x)$, the share of vacancies with $y \leq x$. Finally, conditional on meeting qualified workers, a firm strictly prefers types with higher $x .^{25}$

We assume one model period to be a month to match available US data from the merged basic monthly CPS files. ${ }^{26}$ In general we construct empirical targets corresponding to the years 2011-2012 since our main experimental benchmark, the audit study by Kroft et al. (2013), was conducted over the course of those two years.

We fix some parameters exogenously. In doing so, we are guided by an insight that we return to below, namely that the consequences of discrimination will endogenously depend on the relation between the interview cost and the value of a filled job to an employer. We thus select values which are conservative with regards to the model-generated gains from finding a qualified worker.

To begin with, we set the discount rate to .992 , consistent with an annual interest rate of more than $9 \%$, implying that employers apply a substantial discount to future revenues. This is markedly above commonly used values in the literature such as the $5 \%$ annual discount used in Davis and von Wachter (2011) accounting for the observation that many US employers faced heightened credit constraints in the years 2011-2012 (Duygan-Bump et al. (2015)).

\footnotetext{
${ }^{24}$ Lise and Robin (2017) estimate a flexible production function for a rich model with two-sided heterogeneity. They obtain evidence which supports our simple specification. Specifically, they find that lower worker types find it increasingly infeasible to match with high firm types.

${ }^{25}$ While this is inconsequential for the baseline setup it will matter in the extended environment with multiple applications per vacancy.

${ }^{26}$ For details on how we construct moments from the CPS data, see Appendix B.
} 
Next, we need to calibrate the two separation rates. We set $\delta_{L}$ to $3.8 \%$ to match a monthly separation rate into non-employment (EN) calculated from the CPS during the years 2011-2012. ${ }^{27}$ The second one, $\delta_{H}$, governs the flow of workers out of a job (including job-to-job transitions) and is hence the relevant separation rate from the perspective of an employer who computes the value of a filled job using equation (4). To calibrate it, we compute a $1.6 \%$ monthly probability of making an employer switch (EE) in the CPS following Fallick and Fleischman (2004). Therefore, the relevant separation rate from the perspective of an employer is $5.4 \%$ monthly. Jointly, this generates the empirically observed short duration of a match without inflating the unemployment rate.

As discussed previously, our choice for the value of leisure $b$ is guided by the specific objective of delivering job values (to employers) that compare with those in the literature. $^{28}$ To that end, we compute the value of a filled job to an employer, expressed as a fraction of monthly output, in three leading calibrations of the Diamond-MortensenPissarides (DMP) model. First, it follows from the calibration in Shimer (2005a) that the value of a filled job to an employer corresponds to $57 \%$ of monthly output. For Hagedorn and Manovskii (2008) we obtain a value of 33\%. For Gertler and Trigari (2009), we obtain a value of $97 \%$ of monthly output. ${ }^{29}$

With those targets in mind, we choose $b$ so as to correspond to $96 \%$ of the average monthly output in the cross-sectional distribution. To achieve this, we proceed as follows: We approximate the distributions of both worker and firm types $X$ and $Y$ on 50 grid points on the unit interval, with distributions to be specified in the next subsection. We then add an arbitrarily large constant to output for viable matches-that is, to those with $x \geq y$-which allows us to obtain $\frac{b}{p(x, y)} \approx .96$ for all $x \geq y$ for a scalar $b .{ }^{30}$ Finally, we note that we have not yet chosen a unit of normalization so we report all relevant values relative to the average monthly output in the cross section.

With this normalization in mind, one can readily verify, using the expression for $J(x, y)$ in (4) and our calibrated values for $\beta$ and $\delta_{H}$, that setting $b=.96$ amounts to

\footnotetext{
${ }^{27}$ The separation rate into unemployment (EU)-rather than non-employment (EN) - is substantially lower. We again chose to work with the broader definition so as to generate a conservative value for expected match duration.

${ }^{28}$ In particular, we again point out that choosing $b$ appropriately-in the sense that it delivers a plausible job value-renders the assumption that workers have no bargaining power innocuous with respect to the value of a job.

${ }^{29}$ These objects are straightforward to compute in Shimer (2005a) and Hagedorn and Manovskii (2008) using the flow value of leisure relative to output, along with the bargaining power of the worker and the separation and discount rates. Gertler and Trigari (2009) directly report their value of $J$ which we contrast with monthly output per worker using their calibrated values for the labor share, the separation rate, labor adjustment costs, and the flow value of unemployment.

${ }^{30}$ We thus highlight that worker heterogeneity in our environment is largely about the "extensive margin", namely about whether a worker is qualified for a job. In practice, we shift output by a value of 200.
} 
Table 1: Calibrated Parameters

\begin{tabular}{lll} 
Parameter & Value & Target \\
\hline Discount factor $\beta$ & 0.992 & $9 \%$ annual interest rate \\
Separation rate $\delta_{L}$ & 0.038 & Monthly EN rate CPS. \\
Separation rate $\delta_{H}$ & 0.054 & Monthly EN+EE rate CPS. \\
Interview cost $\kappa$ & 0.10 & $\begin{array}{l}\text { Hiring costs in Silva and Toledo } \\
(2009), \text { Barron et al. (1997) }\end{array}$ \\
Unemployment value $b$ & 0.96 & $\begin{array}{l}\text { Job value in Shimer (2005a), } \\
\text { Hagedorn and Manovskii (2008), } \\
\text { Gertler and Trigari (2009) }\end{array}$ \\
\hline
\end{tabular}

Notes: We use the low value for $\delta_{L}$ when constructing EU flows as given by equations (9) and (10). We use the high value for $\delta_{H}$ when constructing the gains from filling a vacant job, $J(x, y)$ in $(4) . \kappa$ and $b$ are expressed relative to mean output, which corresponds to the cross-sectional average monthly output under the steady state distribution of workers across jobs.

$J \approx .65$. This implies that all employers value a filled job at around $65 \%$ of monthly output. We thus conclude that, by choosing an appropriate value for $b$, our framework gives rise to plausible values of a job to an employer, despite the assumption that workers are held to their outside option.

Perhaps the newest parameter relative to standard models of search in the labor market is the cost of an interview. We appeal to Silva and Toledo (2009) who, using the Small Business Administration Survey, document that employers spend on average 16 hours per hire. Assuming 40 hours of weekly work this corresponds to $10 \%$ of monthly output. We thus set the cost per interview $\kappa=.1$. This is a very conservative upper bound since the interview constitutes only a fraction of the overall costs involved in hiring; more importantly, only a fraction of the interviews conducted lead to jobs implying that the cost per hire exceeds the cost per interview. ${ }^{31}$

The set of externally calibrated parameters is summarized in Table 1.

\footnotetext{
${ }^{31}$ Barron et al. (1997) report the findings from several other surveys attempting to measure screening costs. The largest value we can find, which was originally reported in Barron and Bishop (1985), corresponds to an average of 10 hours spent on evaluating candidates with a standard deviation of 17 . These measures again correspond to the overall time evaluating applicants rather than the interview cost per applicant which is why they constitute upper bounds for $\kappa$.
} 


\subsection{Estimated Parameters and Targets}

The remaining parameters govern the efficiency of the matching function, $\lambda$, the distribution of unobserved heterogeneity among workers, $l(x)$, and the distribution of job openings, $F(y)$. We estimate these fully parametrically using Simulated Method of Moments.

We assume that unobserved ability is distributed $x \sim \operatorname{beta}(A, B)$ with support on the unit interval, where $A$ and $B$ are to be estimated. We assume that vacancies are uniformly distributed across the unit interval, but we allow for one additional degree of freedom: we allow for a strictly positive fraction of job openings to have no skill requirements, that is $F(y)=F(0)+y(1-F(0))$ where $F(0) \geq 0$ is a parameter to be estimated. ${ }^{32}$

We target moments which are informative about these parameters: the aggregate unemployment rate, along with the empirical job finding rate and the experimentally measured callback rate at various durations $\tau$. To guide the search over the parameter space, we employ Markov Chain Monte Carlo following Chernozhukov and Hong (2003) to minimize the log deviations of model-generated moments from their empirical counterparts. We use an identity weighting matrix and report the parameters pertaining to the mean of the converged Markov Chain. ${ }^{33}$ We next discuss how we construct these moments and how they inform the parameters of interest.

Clearly, there is a direct and monotone mapping between the unemployment rate and the contact rate $\lambda$. Our empirical target for the aggregate unemployment rate is $8.5 \%$, again computed using the average unemployment rate in the merged monthly CPS files for 2011 and 2012.

Next, $A$ and $B$ jointly govern the variance and skewness of the distribution of unobserved heterogeneity. We make a heuristic argument about how these higher moments affect the shape of both the unconditional job finding rate and the callback rate. Increasing heterogeneity increases the slope of both job finding and callback rate against unemployment duration since dynamic selection becomes more pronounced. In turn, the skewness of the underlying distribution of heterogeneity governs the convexity of both the job finding and the callback rate as a function of unemployment duration. To see this, note that a distribution with positive skew has few very high $x$ workers and many low $x$ ones. In that case, we should see a sharp initial decline in both hazards and a subsequent flattening. The opposite occurs for a distribution with negative skew. We confirm the

\footnotetext{
${ }^{32}$ We argue, though we have not proven, that the uniformity of $F(y)$ for $y>0$ is a normalization since what matters for the shape of the hazards is the distribution of job openings relative to the distribution of ability. We discuss the motivation for the additional parameter $F(0)$ and how we discipline it quantitatively below.

${ }^{33}$ The remaining details of our implementation follow the descriptions in Lamadon (2016), Jarosch (2015) and Lise et al. (2016).
} 
validity of these conjectured relationships using the large number of model simulations from constructing the Markov Chains.

Finally, we argue that the long-run callback rate informs $F(0)$. To see why, note that the pool of unemployed workers becomes completely dominated by the lowest types in the population as duration grows large. It follows that the callback rate in response to an application by a worker with (very) high $\tau$ corresponds to the fraction of vacancies that are open to employ those with the lowest type $x$. Combined with the assumption that all firms call back duration $\tau=0$ workers, this implies that the long-run decline in the callback rate pins down $F(0)$.

To construct an empirical target for the unconditional job finding rate, we follow Kroft et al. (2015) and estimate the negative exponential relationship between the empirical job finding probability and unemployment duration (in months) in the CPS via weighted nonlinear least squares. That is, we estimate the following functional form for the average job finding probability at duration $\tau$ relative to the average job finding probability of workers who have been unemployed one month or less:

$$
D(\tau)=b_{1}+\left(1-b_{1}\right) \exp \left(-b_{2} \cdot \tau\right)
$$

We use exactly the same functional form when fitting the decline in the callback rate.

Figure 1 plots the raw data (relative to their level in the first month) along with the fitted curve implied by specification (13). Since our model does not speak to dynamic selection on observables we strip out the effects of a variety of observables. ${ }^{34}$ Even doing so, the job finding probability declines by around $50 \%$ during the first year of unemployment. Our empirical estimates are $\hat{b}_{1}=.49$ and $\hat{b}_{2}=.36$. We do not directly target, in an indirect inference sense, the empirical coefficients $\hat{b}_{1}$ and $\hat{b}_{2}$. Instead, we have found it more informative to target equally weighted values of $D(\tau)$ as obtained through equation (13) at durations $\tau \in[0,25]$ months. ${ }^{35}$

Our target for the callback rate is taken directly from Kroft et al. (2015) who fit the nonlinear specification (13) to the experimental evidence in Kroft et al. (2013). Their reported estimates are .425 for the intercept parameter $b_{1}$ and .199 for the slope parameter $b_{2}$. Our framework generates an exact counterpart to the empirical callback rate as tracked in the audit studies: We track the fraction of job openings which follow up on an application

\footnotetext{
${ }^{34}$ This has an important consequence for the incidence of long term unemployment in our model. In particular, our setup will generate too little long term unemployment since it ignores dynamic selection along observables as a force towards duration dependence in the job finding rate. We revisit this issue in the discussion of our quantitative results.

${ }^{35}$ The reason is that "minimizing the distance" between model generated and empirical coefficients is not equivalent to minimizing the distance between the implied job finding rates.
} 
Figure 1: Relative job finding Probabilities by Unemployment Duration

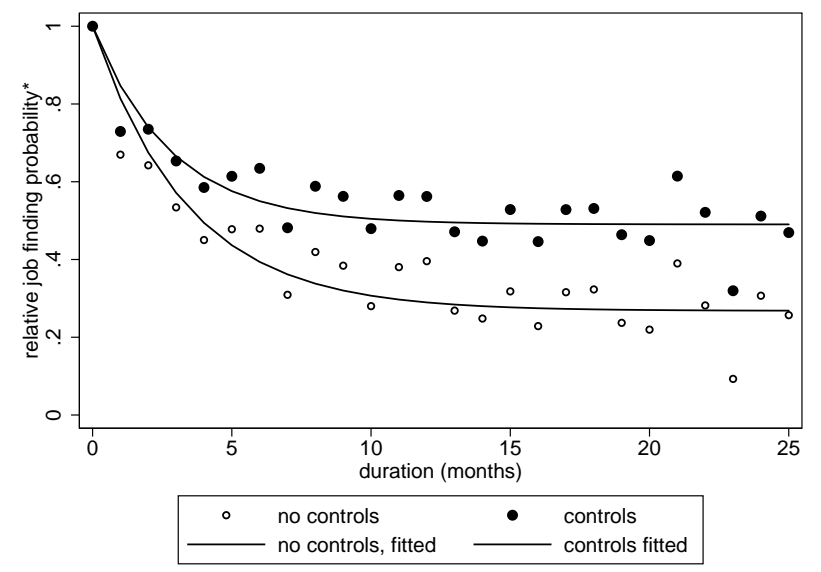

Notes: We use pooled CPS data from 2011-2012. For the curve without controls for observables, we regress the job finding rate on duration dummies as well as year and month dummies. We then take the average job finding rate at duration zero, and compute implied job finding rates at durations $\tau>0$ by adding the coefficients on the duration dummies to the job finding rate at duration $\tau=0$. We then normalize the job finding rates by the job finding rate at duration $\tau=0$. For the curve which controls for observable characteristics, we run the same regression, but add additional controls which include: gender dummies, age group dummies (16-24,25-34,35-44,4554, and 55-64), three race dummies (white/black/other), five education category dummies (less than high school, high school graduate, some college, college graduate, and other), and gender interacted with all these covariates. We then subtract the new coefficients on duration from the same mean as before and calculate the normalized job finding rate. For more details, see Appendix B. 
Figure 2: Heterogeneity and Selection

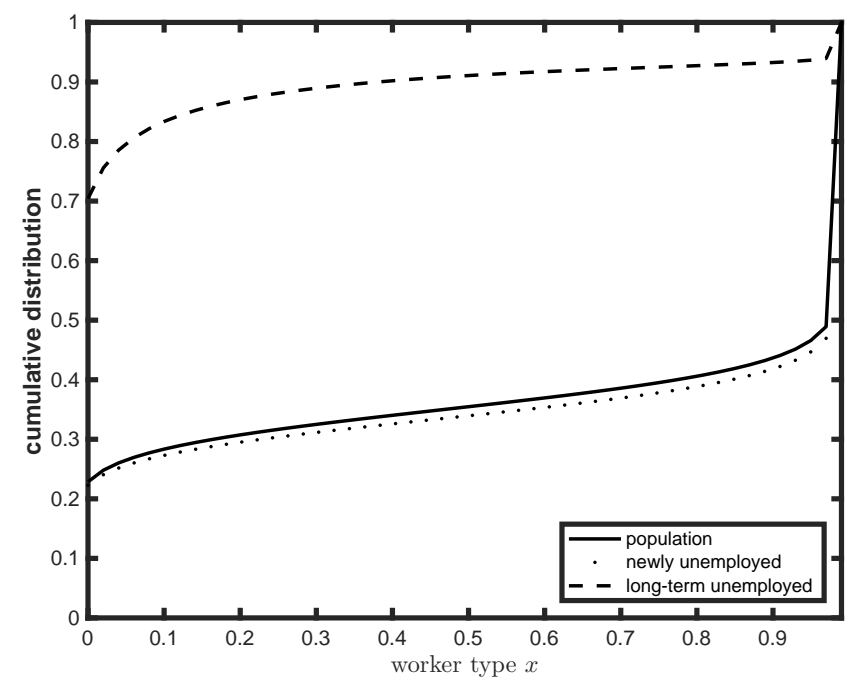

Notes: The solid line plots $l(x)$, the distribution of ability in the population. The dotted line plots the corresponding object among newly unemployed workers with $\tau=0$. The dashed line does so for long term unemployed workers with $\tau \geq 6$.

with an interview invitation, depending on current duration $\tau$. Again, our targets correspond to the actual relative callback rates at months $\tau \in[0,25] .{ }^{36}$

\subsection{Estimation Results and Model Fit}

Our parameter estimates governing the population distribution of ability are $\hat{A}=.1150$ and $\hat{B}=.0630$. Jointly, those estimates imply a distribution of heterogeneity that is close to bimodal with most workers either qualified for most jobs or only qualified for jobs with little, if any, skill requirement. This can as can be seen in figure 2 which plots the cumulative distribution of the fraction of jobs a worker is qualified for. The figure implies that around one quarter of the workforce is solely qualified for the fraction $F(0)$ of jobs that have effectively no skill requirements. ${ }^{37}$ In turn, roughly one half of the population is qualified for all jobs they apply for. Effectively, this arises due to the sharp initial drop-off followed by a subsequent flattening in both targets.

Figure 2 also plots the skill composition separately for the newly and long term unem-

\footnotetext{
${ }^{36}$ That is, we target the decline in the callback rate, not its level. The model does not capture the level since all firms in our framework call back workers with duration $\tau=0$. We argue that the slope captures the degree of dynamic selection and statistical discrimination and hence the key object of interest.

${ }^{37}$ We estimate $\hat{F}(0)=.3979$ as discussed below. The both ends of the distribution arises because we approximate the distribution on a grid.
} 
ployed. Since all jobs are equally likely to get destroyed, skills among the newly unemployed equal those of the employed which is why they first order stochastically dominate the population distribution. Finally, the long term unemployed are largely selected from low- $x$ types, reflecting the dynamic selection process leading to the declining job finding and callback rates we turn to next.

The model closely captures the normalized decline in the job finding rate we measure in the CPS and target in the estimation. Figure 3 plots the estimated decline in the job finding rate in the model against the empirical target.

Figure 3: The Decline in the Job Finding Rate

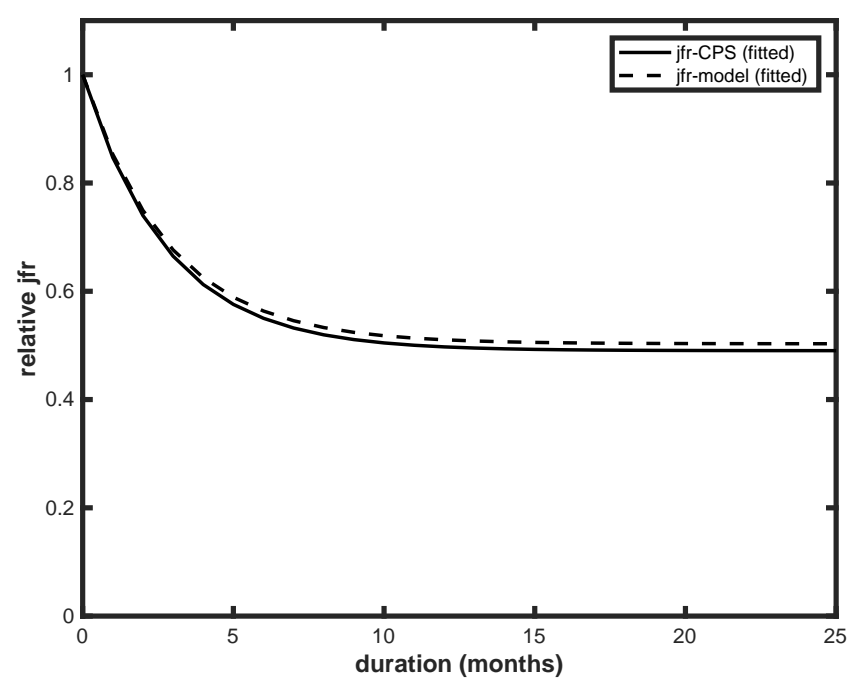

Notes: Average job finding rates (normalized to duration $\tau=0$ ) as approximated by equation (13), in both the model and the data as described in Figure 1.

The framework generates an aggregate unemployment rate of $8.43 \%$ which is only very slightly below our empirical target of $8.5 \%$. The associated parameter estimate for the contact rate is $\hat{\lambda}=.6071$.

We next turn to the empirical fit of the model-generated callback rate which is likewise targeted. As we show in figure 4, the model closely captures the duration dependence in callbacks as reported in Kroft et al. (2015). We highlight that the long-run stabilization of the normalized callback rate slightly above $40 \%$ is what disciplines a parameter estimate of $\hat{F}(0) \approx .4$. In words, our model generates a long-run relative callback rate of $40 \%$ by associating a similar fraction of jobs with no skill requirements. 
Figure 4: The Decline in the Callback Rate

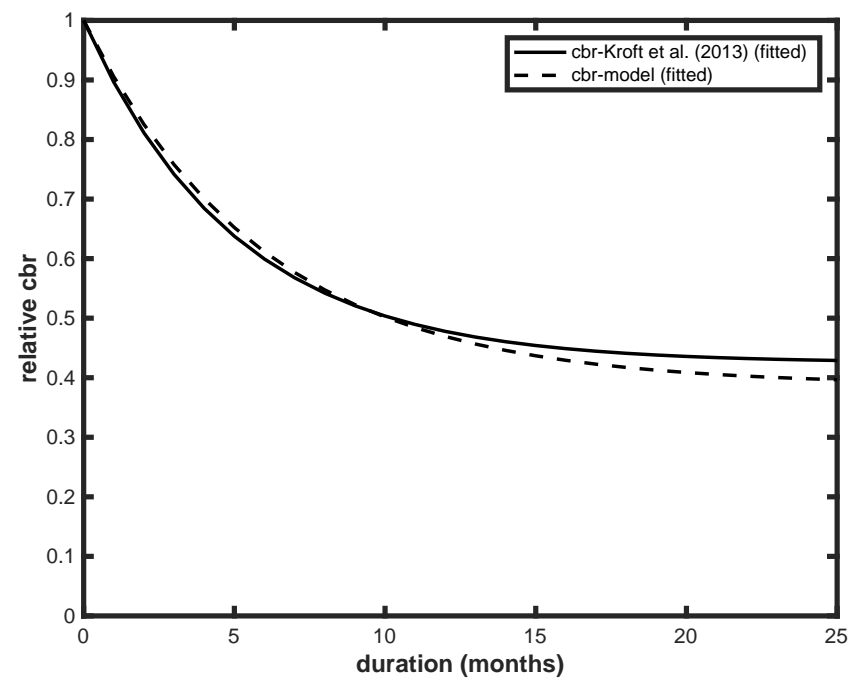

Notes: Average callback rates (normalized to duration $\tau=0$ ) as approximated by equation (13) in both the model and the experimental data as reported in Kroft et al. (2015).

\section{The Robustness of the Experimental Evidence}

The external validity of the evidence in Kroft et al. (2013) is far from established so we contrast it with several other audit studies on the relation between unemployment duration and the likelihood of a callback which follow a similar approach.

First, the audit studies in Ghayad (2013) and Oberholzer-Gee (2008) both find large and monotonic declines in the probability of a callback as unemployment duration increases. Oberholzer-Gee (2008) reports a 31\% decline in callbacks as unemployment duration increases from 6 to 18 months in a study conducted in Switzerland. In the US, Ghayad (2013) reports a decline of roughly $46 \%$ as unemployment duration decreases from 1 to 6 months, closely connecting with our benchmark evidence in Kroft et al. (2013). Importantly, Ghayad (2013) shows that for resumes with no relevant industry experience the decline in callbacks over the same horizon more than twice exceeds the decline for resumes with experience. In Sweden, Eriksson and Rooth (2014) find large drops in callbacks after 9 months of unemployment for medium and low skill jobs, but not for high skilled jobs.

Most recently, Farber et al. (2016) find no evidence of duration dependence in callbacks. However, Kroft et al. (2013) work with relatively low-skilled young workers whereas Farber et al. (2016) construct resumes of college educated older workers with more work experience. 
We thus argue that a common picture emerges that can be interpreted in the context of our theory: The larger the dispersion of unobservables, the larger the impact of correlated observables (such as unemployment duration) on the callback decision, as there is less reason to condition the interview on unemployment duration once a resume contains a large amount of other information. ${ }^{38}$

The experimental evidence, which is the starting point for our exercise, thus paints a broadly consistent picture when viewed through the lens of our environment. It documents substantially declining callback rates in various different years and countries; and the impact of unemployment duration on callbacks weakens once employers have more additional information available, consistent with our modeling strategy of mapping the dynamic evolution of unobservables on the observable unemployment duration, $\tau$.

\section{The Callback Rate and Aggregate Conditions}

We conclude this section by comparing the implications of local labor market conditions in our framework against the empirical evidence in the spirit of an over-identification test. Kroft et al. (2013) find a substantially lower slope for the callback rate when the local unemployment rate is high. That is, if the labor market has slack, duration carries less of a signal about unobserved quality and firms discriminate less against the long term unemployed. The same qualitative logic holds in our model. Here, we check whether our framework also captures the quantitative impact of local labor market conditions.

To this end, we hold all estimated parameters fixed and adjust the contact rate $\lambda$ so as to capture (in steady state) the average unemployment rate in the high-unemployment MSA sample studied separately in Kroft et al. (2013). We again compare the normalized and fitted callback rate in our model against the callback rate reported in Kroft et al. (2015). As Figure 5 shows, our framework broadly captures the response of discrimination to a slackening of the labor market. ${ }^{39}$

The variation by labor market conditions is a key empirical object that supports our framework's mechanism: discrimination is an endogenous response to dynamic sorting along unobservables, a force that becomes much weaker when the labor market has slack. That our framework quantitatively captures this evidence without targeting it in the estimation is thus reassuring for our approach.

\footnotetext{
${ }^{38}$ This immediately relates to the variation of the evidence by experience. To see how it relates to education, note that the log earnings variance patterns documented in Meghir and Pistaferri (2004) are declining in educational achievement which suggests larger residual variation in unobservables for the low skilled.

${ }^{39}$ The model-generated callback rate falls too much relative to the empirical evidence, but this is by construction: since the share of low firms $F(0)$ is unchanged, the callback rate must fall to the same long-run rate as in the baseline following the identification arguments made earlier.
} 
Figure 5: Varying Labor Market Conditions

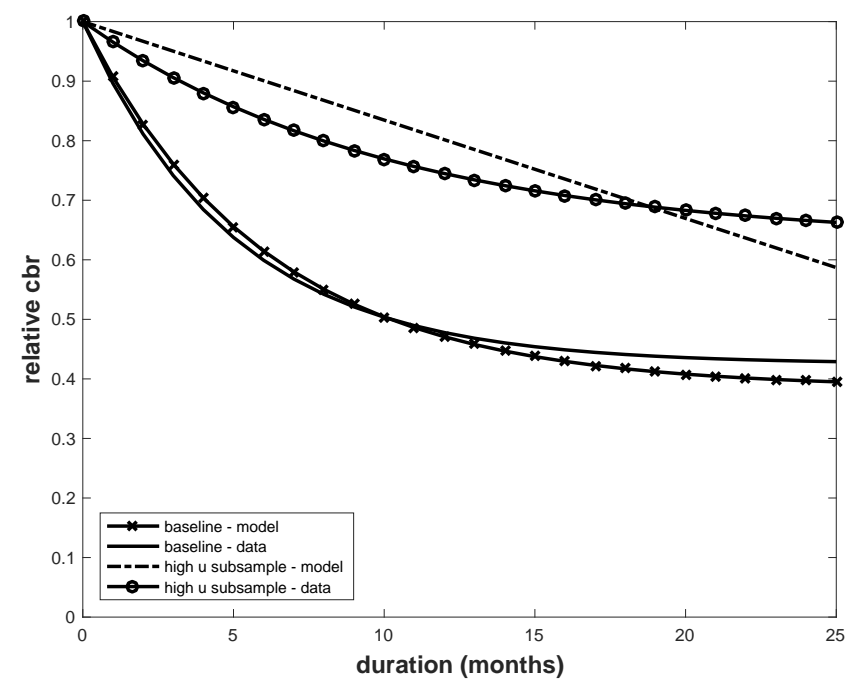

Notes: The baseline replicates Figure 4. The high unemployment subsample adjusts $\lambda$ so as to capture the unemployment rate in the High Unemployment MSAs listed in Kroft et al. (2013). Using the Bureau of Labor Statistics Local Area Unemployment Statistics, we compute a (population weighted) average unemployment rate of $17.6 \%$ in the respective MSAs over the time period of August 2011 to July 2012. We then plot the model generated callback rate (normalized, fitted) under the high-unemployment steady state to the empirical counterpart reported in Kroft et al. (2015). 
In sum, the estimated model environment gives rise to same, quantitatively large extent of duration dependence in callbacks documented in our benchmark experiment and various other audit studies. In other words, if one were to conduct a resume audit study in the labor market modeled here, the results would closely resemble the ones reported in the experimental literature.

\section{The Effects of Discrimination on the job finding Rate}

In this section, we use the estimated model to quantify the contribution of statistical discrimination to duration dependence in job finding rates and to the incidence of long term unemployment.

\subsection{Main Results}

To quantitatively gauge the impact of discrimination on key labor market outcomes, we contrast duration dependence in the job finding rate and the incidence of long term unemployment in our full model with an alternative allocation that displays no discrimination. Specifically, we study a labor market where interviews are free and all employers hence interview and learn about applicants of all durations $\tau$. To do so, we set $\kappa=0$ while holding all other parameters fixed according to the previous section and contrast several steady state features from this counterfactual, "full information" economy with our benchmark model that has positive interview costs. The resulting allocation is equivalent to one where a worker exits unemployment whenever she is qualified for a job. ${ }^{40}$ Table 2 contrasts the no-discrimination environment with our baseline case.

If interviews are free, there is no more statistical discrimination at the callback stage and workers who apply to a job they are qualified for exit unemployment with certainty. The first three columns of Table 2 report the unconditional job finding rate at various unemployment durations for the two environments. The first column reports the average job finding rate for the short-term unemployed workers (with duration less than 3 months), the second does so for those with medium-term duration (with duration 3-5

\footnotetext{
${ }^{40}$ We have also experimented with an alternative counterfactual where all active firms must interview all applicants, independent of their unemployment duration, in the spirit of some of the policy initiatives that were introduced to combat long term unemployment (UADA (2012)). Such a counterfactual, of course, makes the overall hiring process more expensive and, as a consequence, causes some firms to opt out from interviewing altogether. We thus only report results for the free-interview scenario which can be thought of as an upper bound relative to other, more costly, policy interventions. We also highlight that our counterfactual gives rise to the same allocation as an alternative first best benchmark where interviews remain costly, but are conducted on all qualified applicants.
} 
Table 2: The Consequences of Discrimination

\begin{tabular}{lcccc} 
& $\mathrm{jfr}_{0-2}$ & $\mathrm{jfr}_{3-5}$ & $\mathrm{jfr}_{6+}$ & ltu \\
\hline baseline & 45.328 & 30.837 & 25.341 & 0.846 \\
\hline full information & 45.335 & 31.819 & 25.979 & 0.784 \\
\hline
\end{tabular}

Notes: All results are expressed in percent and correspond to steady states. First row: Baseline model with discrimination. Second row: Counterfactual with free interviews. First column: Average monthly job finding rate of workers with unemployment duration $\tau=0-2$ months. Second Column: $\tau=3-5$ months. Third Column: $\tau \geq 6$ months. Fourth column: Fraction of the population in long term unemployment, that is with $\tau \geq 6$.

months), while the third reports the equivalent for the long term unemployed (with duration exceeding 6 months).

The most important aspect about the contrast between the job finding rate under full information and in our baseline environment is that the differences are small. Under full information, firms call back at all durations implying very large increases in callbacks: The long term unemployed get interviewed more than twice as often and even those with medium-term duration receive almost $60 \%$ more callbacks. Yet the rate at which the unemployed find a job increases only by around 3\% for those with medium and high duration.

The final column of the table contrasts our baseline with the no-discrimination benchmark in terms of the incidence of long term unemployment. ${ }^{41}$ The benchmark with no discrimination has higher job finding rates at all durations and consequently less long term unemployed workers. However, the difference in the incidence of long term unemployment amounts to less than $8 \%$, substantially less than one might suspect from the experimental observation that monthly callbacks decline by over $50 \%$ by the time a worker enters long term unemployment.

As pointed out above, our model generates substantially too little long term unemployment: The share of unemployed workers with duration exceeding half a year in our model is only slightly more than $10 \%$ while, in the data, this ratio was closer to $20 \%$ prior to the Great Recession and increased to over $40 \%$ at the peak of the recession (Kroft et al. (2015)). As we have argued above this discrepancy largely follows from eliminating dynamic selection along observables when constructing our target for unconditional

\footnotetext{
${ }^{41}$ As can be inferred from the last column, our baseline model generates a rate of long term unemployment significantly below what the rate of long term unemployed was in the U.S. during our sample frame. We return to this observation below.
} 
duration dependence in the job finding rate as depicted in figure 1 . We have chosen to focus on the residual degree of duration dependence since that is the component which reflects unobservables and hence drives discrimination. It is thus also natural to quantify the extent to which discrimination generates the type of long term unemployment that is associated with dynamic selection in unobservables. Nevertheless, we have repeated the exercise of removing the interview cost for the high-unemployment calibration studied in figure 5 . There, $34.75 \%$ of all unemployed have been out of a job for more than 6 months, close to the incidence of long term unemployment during the great recession. Yet when we again set interview costs to zero and remove all discrimination the counterfactual share changes only slightly, falling to $34.57 \%{ }^{42}$

To lead up to the next subsection, we briefly discuss how the impact of discrimination differs across workers. To that end, we report the increase in the job finding rate in our counterfactual experiment for different worker types, all of them unemployed for 6 months: A worker at the bottom of the skill distribution has exactly the same job finding rate, with or without discrimination. As can readily be seen from figure 2 those workers constitute the vast majority of the long term unemployed. In turn, a worker at the top of the skill distribution experiences a very large increase in the unemployment exit rate of $92.0 \%$. Even a worker who is only qualified for $70 \%$ of all vacancies experiences an increase of $35.4 \% .{ }^{43}$

This highlights that our aggregate results mask substantial heterogeneity: High types suffer substantially from discrimination if they "fall through the cracks" and become long term unemployed. In contrast, low types do not experience any increase in their job finding rate which is in the background of our moderate findings for the aggregate labor market. The reason is that low types are not qualified for the job openings that opt not to interview the long term unemployed. In turn, the high types that suffer the most from discrimination are rarely long term unemployed which is both the reason for why firms discriminate and why that discrimination is without adverse consequences for the majority of workers constituting the long term unemployed. Nonetheless, statistical discrimination can have drastically negative consequences for the part of the workforce that tends to exit unemployment quickly.

\footnotetext{
${ }^{42}$ As will become clear in section 4.3 , the reason behind these findings is that the key force that generates false negatives operates independently of the level of the job finding rate.

${ }^{43}$ Both the highest worker type as well as the worker who is qualified for $70 \%$ of jobs have a job finding rate of $31.6 \%$ at duration $\tau=6$ in the baseline model. The lowest type worker has a job finding rate of $24.2 \%$ in the baseline at duration $\tau=6$, and experiences no change in their job finding rate in the full information counterfactual.
} 


\subsection{Decomposing Duration Dependence}

Before turning to a discussion of why our counterfactual suggests only modest consequences of discrimination we discuss a complementary way of gauging the causal impact of statistical discrimination - that is, the decline in callbacks-on the job finding rate. In particular, we offer an organized decomposition of duration dependence in the job finding rate into a purely compositional and a structural component, the latter fully driven by statistical discrimination.

To do so, we note that the job finding rate of an $(x, \tau)$ worker is given by $f(x, \tau)=$ $\lambda \int_{y \in I(\tau) \cap H(x)} d F(y)$. We can then let $\bar{f}_{\tau}(t) \equiv \frac{1}{\int u(x, \tau) d x} \int f(x, t) u(x, \tau) d x$ denote the average job finding rate at duration $t$ when skills are distributed according to the population of unemployed workers at duration $\tau$. Duration dependence in the job finding rate as measured in the data is then given by

$$
D(\tau) \equiv \frac{\bar{f}_{\tau}(\tau)}{\bar{f}_{0}(0)} .
$$

Of course, $D(\tau)$ reflects two forces, namely that the distribution of types changes as $\tau$ progresses, but also that the callback rate declines with $\tau$. In order to isolate the respective contribution of these forces to $D(\tau)$, note that we can expand $D(\tau)$ into

$$
D(\tau)=\frac{\bar{f}_{\tau}(\tau)}{\bar{f}_{\tau}(0)} \frac{\bar{f}_{\tau}(0)}{\bar{f}_{0}(0)}
$$

These two objects separate $D(\tau)$ into a structural and a compositional component. The first fraction quantifies how the average duration $\tau$ job finding rate of a representative duration $\tau$ cohort compares to their own average job finding rate at the beginning of the unemployment spell. It thus purely isolates the force duration exerts on the job finding rate of the relevant workers at duration $\tau$. On the other hand, the second fraction isolates purely compositional changes. It reports the decline in the job finding rate from duration 0 to $\tau$ which is attributable to compositional changes only, holding the individual job finding rates constant at their duration 0 level. Thus, equation (15) allows us to exactly decompose duration dependence in the job finding rate into its two drivers.

This decomposition is complementary to the exercise in the previous subsection, as the distribution of types in unemployment itself reflects structural forces, that is discrimination. The decomposition in (15) fixes the evolution of the distribution of types according to the equilibrium with discrimination. On the other hand, the counterfactual exercise in the previous section takes the full equilibrium response of the distribution into account.

Figure 6 offers the decomposition delivered by Equation (15). To plot it, we proceed as 
Figure 6: Duration Dependence - A Partial Equilibrium Decomposition

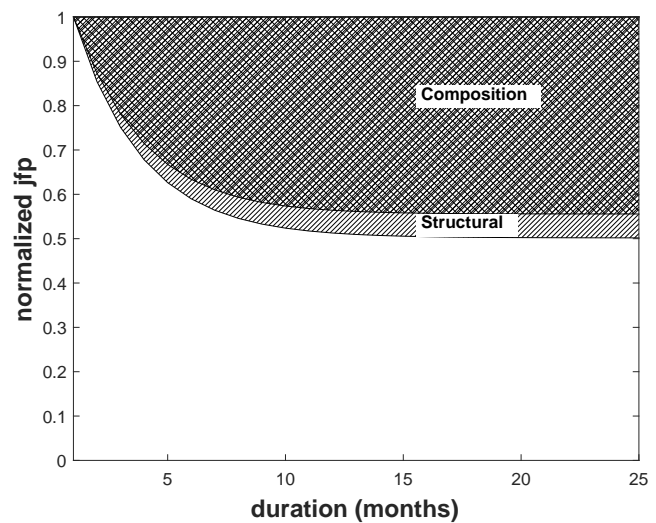

Notes: The lower envelope plots $D(\tau)$. The line separating the two shaded areas plots $\frac{\bar{f}_{\tau}(0)}{\bar{f}_{0}(0)}$.

follows. The lower envelope plots the normalized job finding rate, $D(\tau)$, the object to be decomposed. We next plot $\frac{\bar{f}_{\tau}(0)}{\bar{f}_{0}(0)}$, that is the purely compositional component only. As is readily visible from equation (15), doing so decomposes the overall decline in $D(\tau)$ into a compositional (upper area) and structural (lower area) component.

The results are consistent with our results in the previous subsection. While statistical discrimination indeed introduces a negative structural component into the average job finding rate, the contribution is modest and most of the declines are driven by compositional changes.

The structural component $\frac{\bar{f}_{\tau}(\tau)}{\bar{f}_{\tau}(0)}$ is above .9 at all horizons which can be quantitatively interpreted as follows: Workers unemployed at duration $\tau$ experience, on average, less than a $10 \%$ decline in their chances of finding a job relative to duration 0 as a result of duration per se. ${ }^{44}$ As a consequence, the bulk of the decline in $D(\tau)$ is due purely to compositional changes as is evidenced in figure 6.

To conclude this section, Figure 7 tracks the evolution of the distribution of worker types and the cutoff firm as duration progresses. Due to dynamic selection the expected worker type deteriorates as $\tau$ increases. As an endogenous response, less and less firms are willing to follow up on an application. What is key, however, is that the contraction of the interview set-that is, the decline in the callback rate-only affects those that are actually qualified for firms with skill requirement above the cutoff firm. That is, only

\footnotetext{
${ }^{44}$ This stands in sharp contrast to what one may infer by studying $\frac{\bar{f}_{0}(\tau)}{f_{0}(0)}$. Such a measure isolates the force duration exerts on the job finding rates of a representative short-term unemployed worker. Indeed, this measure declines by almost as much as $D(\tau)$ in our calculations and quantifies the experience of representative types "falling through the cracks". But it is not a suitable measure to quantify the consequences of statistical discrimination because it ignores its root cause, namely dynamic selection.
} 
Figure 7: Duration Dependence
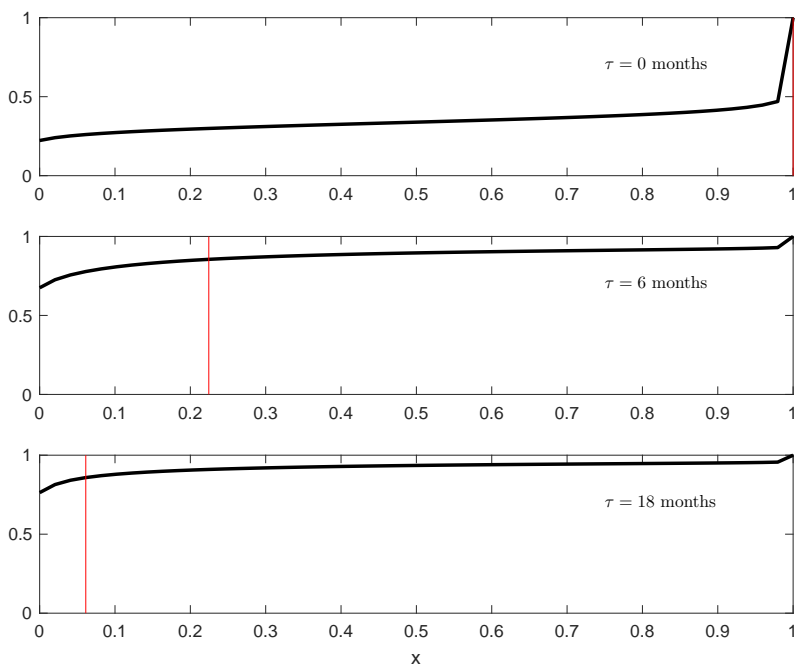

Notes: Cumulative distribution of worker types $x$ in the population of unemployed workers at various durations $\tau$. The red bar indicates the productivity $y$ of the threshold firm which is indifferent about interviewing workers with duration $\tau$. Firms with productivity exceeding that of the cutoff firm do not call back. Note that firms with no skill requirements account for a strictly positive fraction of job openings which is not visible in the figure.

those with skill to the right of the cutoff firm are adversely affected by the disappearing callbacks. As is evident from Figure 7, those are few while the vast majority of the long term unemployed are entirely unaffected, despite experiencing a large drop-off in their callback rate.

To summarize, these results imply that the decline in the job finding rate in our model is largely a result of dynamic sorting along unobservables. Statistical discrimination is primarily a response to dynamic (adverse) selection rather than a cause of structural duration dependence. For the relevant group of unemployed workers, discrimination has only a modest impact on job finding rates, despite the very large decline in callbacks diagnosed in the experimental literature. The firms that begin to discriminate do so because there are few workers they can form viable relationships with left in the pool of unemployed. In turn, this implies that the incidence of false negatives - no-callback events that prevent a worker from being hired - is much smaller than the incidence of no-callback events as tracked by an audit study. However, Figure 7 also highlights that discrimination indeed has very painful consequences for high $x$ types which are qualified for a wide range of jobs and fail to find a job early in a spell. 


\subsection{Intuition}

This section offers a simple formal argument that exactly shows the tradeoffs firms face when deciding on a callback. We use that tradeoff to shed light on why our quantitative results point to a limited impact of discrimination on labor market flows.

To that end, let $\bar{y}(\tau)$ denote the threshold firm which is indifferent about interviewing workers of duration $\tau$. From (6), the indifference condition can be expressed as

$$
P\left[x>\underline{\mathbf{x}}_{\bar{y}(\tau)} \mid \tau\right] \mathbf{E}\left(\frac{p(x, \bar{y}(\tau))-b}{\left(1-\beta\left[1-\delta_{H}\right]\right)} \mid x>\underline{\mathbf{x}}_{\bar{y}(\tau)}, \tau\right)=\kappa .
$$

In words, a firm is indifferent about a callback if interview costs equal their expected gains given by the probability of finding a qualified candidate times the conditional expected payoff. Equation (16) implies that, if interview costs are low relative to the value of viable employment relationships, a firm only discriminates against duration $\tau$ workers if it is unlikely to find a qualified match among them.

We next use this expression to establish quantitative bounds on the fraction of workers that are adversely affected by discrimination. To do so, note that $\underline{x}_{\bar{y}}(\tau)=\bar{y}(\tau)$ under our production function. This implies that the term in squared brackets in equation (16) corresponds to the fraction of unemployed duration $\tau$ workers that are qualified for at least some of the jobs that dismiss duration $\tau$ workers for interviews. Using our calibration, we can establish the following numerical bounds for this object, 45

$$
P[x \geq \bar{y}(\tau) \mid \tau] \in[.137, .176]
$$

In words, a firm starts discriminating once the chances of finding a suitable worker drop below around $15 \%$. In turn, this implies that at all durations durations $\tau$, the vast majority of workers do not experience any discrimination that has adverse consequences for the chances of finding a job. ${ }^{46}$

Taken together, the quantitative analysis of equation (16) highlights the key tradeoff and why it generates only modest consequences of discrimination: The present value of a viable employment relationship (the term in brackets) largely exceeds the cost of an interview $\kappa$. This makes missed opportunities of forming a viable match-a false negative-costly relative to an interview that does not lead to a hire. Consequently, firms try to avoid false negatives and only discriminate if the chances of finding a qualified candi-

\footnotetext{
${ }^{45}$ For simplicity, we use the global limits for $p(x, y)$ in establishing the bounds.

${ }^{46}$ Even those who are adversely affected suffer from false negatives only when applying to a job-opening with $y$ such that $\bar{y}(\tau) \leq x \leq y$, which limits the extent to which their job finding rate deteriorates.
} 
date are slim. This implies that few interviews lost to discrimination would have turned into job.

Our calibration choices were deliberately conservative with regard to this particular tradeoff: As can be seen from equation (17), the value the firm derives from a viable employment relationship is only about 6-7 times the cost of an interview. From (16), this reflects that we have chosen a low discount factor $\beta$, a high separation rate $\delta_{H}$, and a low flow payoff to the firm, $p(x, y)-b$. The equation also highlights in which type of labor markets one may expect discrimination to have particularly adverse consequences for workers: In those with short-lived jobs, and in those where interview costs are large relative to the flow value generated by a qualified worker.

To conclude, the relation between the costs of an interview and the net present value of filled jobs to a firm suggests that firms who are not interviewing do so because they are unlikely to find a suitable partner. It follows that the incidence of false negatives is limited and the decline in callbacks causes a decline in the job finding rate to only a modest extent.

\section{Extended Quantitative Model}

In this section, we extend the basic model along two important dimensions of the job search process which are likely to generate more drastic consequences of discrimination. We re-estimate the framework and revisit consequences of discrimination in the richer environment.

We first extend the model by allowing for general human capital to depreciate during unemployment and appreciate during times of employment. As before, a false negative may subject workers to longer unemployment spells. However, if human capital deteriorates, the false negative may also lower a worker's future employment rate, which again feeds back into the evolution of her abilities. The inclusion of human capital dynamics may therefore generate a forceful multiplier through which discrimination at the interview stage may affect the cross-sectional distribution of ability and job finding rates, and hence the incidence of long term unemployment.

Second, we allow firms to receive multiple applications per job opening, and workers' applications can potentially crowd each other out. This environment may well give rise to a much larger impact of firms' interviewing decisions on structural duration dependence. In our baseline model, a firm discriminates based on duration only if it is quite certain that the worker is not qualified. With multiple applications, a firm discriminates against a worker it might be perfectly willing to interview otherwise, as soon as it has another 
applicant that is even more likely to be qualified, but has shorter duration. It follows that potentially many more workers that would have been hired ex post are not invited for an interview, solely as a consequence of their unemployment duration. ${ }^{47}$

We maintain the assumption that workers have no bargaining power and homogeneous outside option $b$. For exactly the same logic as in the baseline model, firms thus continue to pay workers a wage $w(x, y, \tau)=b$ and the value of a job to a firm is given by

$$
J(x, y, \tau)=p(x, y)-b+\beta\left(1-\delta_{H}\right) \mathbf{E}_{x^{\prime} \mid x, e} J\left(x^{\prime}, y, \tau\right) .
$$

The expectations operator accounts for the stochastic evolution of ability that depends on a workers employment status, $e$ in this case. We also maintain the assumption that $p(x, y)$ is additively separable for $x \geq y$ as assumed in equation (12).

As before, an unemployed worker's resume makes contact with a job opening at rate $\lambda$. There are $V$ such job openings at any point in time, distributed according to $F(y)$. However, now a single job opening may receive multiple applications due to coordination frictions. As before, the only relevant information on a resume is the applicant's current unemployment duration $\tau$. In case a job opening receives more than one application, the firm can interview multiple workers, paying $\kappa$ for each interview. As a consequence, being qualified for a job and receiving an interview are no longer sufficient for a worker to exit unemployment; she also needs to be the most able candidate of those who receive an interview.

The firm's optimal interviewing strategy is the key object which determines equilibrium job finding rates in this environment, and we therefore describe this strategy in some detail. The firm begins by deciding whether to interview any of its applicants. It does so as long as it receives at least one application such that expected surplus covers the interview cost, as given in inequality (6). Dynamic selection of worker types in unemployment again implies that expected surplus declines with unemployment duration. Thus, firms $y$ that receive only one single application continue to follow a cutoff rule and call back an applicant if duration $\tau$ falls below a duration cutoff $\bar{\tau}_{y}$, defined as the highest $\tau$ such that

$$
\int \max \{J(x, y), 0\} \mu\left(x \mid \bar{\tau}_{y}\right) d x \geq \kappa .
$$

As another consequence of dynamic selection, if the firm receives more than one appli-

\footnotetext{
${ }^{47}$ Any extension that allows workers to actively respond to potentially adverse consequences from discrimination would lead us to find less of an impact of discrimination. This pertains to cases with endogenous search intensity and reservation wages, the latter subject to the empirical caveat discussed above. In either, workers actively avoid "falling through the cracks"; as a consequence, removing discrimination has a smaller effect and may even result in an increase in long term employment.
} 
cant it is optimal for the firm to rank them according to duration. That is, if it receives more than one application with duration less or equal than $\bar{\tau}_{y}$, the firm interviews the lowest duration worker first. After having learned that applicant's ability $x$ the firm can proceed to evaluate the next applicant in the ranking. We make the assumption that by interviewing another candidate the firm does not lose the option of hiring any of the previously interviewed candidates. Thus, the firm hires the interviewee with the highest joint surplus $J(x, y)$, as long as at least one is qualified, $x \geq y$.

To characterize firm behavior, let $\hat{x}$ denote the ability of the highest $x$ worker a firm has already interviewed for a given job opening. The firm then proceeds to interview the next worker in the queue with duration $\tau$ iff

$$
\int_{x} \max \{J(x, y)-J(\hat{x}, y), 0\} \mu(x \mid \tau) d x \geq \kappa .
$$

Firm $y$, whose best candidate thus far has skill $\hat{x}$, calls back another worker with duration $\tau$ if the expected net gains from doing so exceed the cost. If the inequality is not satisfied for any worker left in the queue the firm stops interviewing and hires $\hat{x}$ if $\hat{x} \geq y$. Note that for sufficiently high $\hat{x}$ it may well be that the above inequality does not hold for any $\tau \geq 0$, so the firm stops interviewing.

In a slight abuse of notation, let $u$ denote the measure of unemployed workers and hence $\frac{\lambda u}{V}$ the measure of applications. If the economy displays coordination frictions and workers randomly apply to vacancies a standard argument implies that any given job opening receives exactly zero applications with probability $\exp \left(-\frac{\lambda u}{V}\right)$ (see Shimer (2005b)). Let $z(x, y, \tau)$ be the measure of unemployed workers which, if they apply for the same job $y$, prevent a worker $(x, \tau)$ from being hired by firm $y$. They may do so for several reasons: They may have lower duration and ability high enough such that the firm does not interview duration $\tau$ applicants. Or, if both get interviewed, they may crowd out worker $(x, \tau)$ because they have more skills. We delegate the exact derivation of $z(x, y, \tau)$ to appendix $C$. Importantly, the probability that any given job opening receives exactly zero such applications is then given by $\exp \left(-\frac{\lambda z(x, y, \tau)}{V}\right)$. As a consequence, the job finding rate for a worker with ability $x$ and duration $\tau$ can be written as

$$
f(x, \tau)=\lambda \int_{y \in I(\tau) \cap H(x)} \exp \left(-\lambda \frac{z(x, y, \tau)}{V}\right) d F(y) .
$$

In words, a worker makes contact with some job opening $y$ at rate $\lambda$. A necessary condition for unemployment exit is that the worker is qualified for the job and the firm is generally willing to interview her, $y \in I(\tau) \cap H(x)$. But this is no longer sufficient since the firm may receive other applications which crowd out worker $(x, \tau)$. Consequently, 
conditional on applying to a firm $y$, a worker only exits if there are no other applications from such competitors, which is captured by $z(x, y, \tau)$.

We also report the corresponding value functions for both employed and unemployed workers, the flow balance equations governing the steady state distribution of worker types across jobs, and the extended definition of equilibrium in appendix $C$.

\subsection{Quantitative Implementation}

We fully re-estimate the extended model using the same empirical targets and the same estimation strategy we detail in Section 3. For the quantitative implementation, we again approximate the distributions of both worker and firm types on a grid, but we reduce the number of grid points to 10 , due to computational reasons. ${ }^{48}$ We maintain the same support as in the baseline, and thus do not alter our calibrated values for interview costs and leisure, $\kappa$ and $b$. We also do not alter the calibrated values for $\beta, \delta_{L}, \delta_{H}$.

We follow Ljungqvist and Sargent (1998) in assuming that, if workers have ability $x \in$ $\{\underline{\mathrm{x}}, \ldots, \bar{x}\}$, then while employed their ability increases from $x$ to $\min \{x+1, \bar{x}\}$ with probability $\phi_{e}$. Similarly, while unemployed, their ability decreases from $x$ to $\max \{x-1, x\}$ with probability $\phi_{u}$. Of course, this implies that there is no longer any permanent component to worker productivity.

The parameters to be estimated are now $\left\{\phi_{e}, \phi_{u}, \lambda, F(0), V\right\}$. To do so, we target the same empirical targets as previously, namely the decline in the job finding rate, the decline in the callback rate as measured in Kroft et al. (2013), and the overall unemployment rate. ${ }^{49}$ Our arguments linking the parameters to these targets remain largely unchanged. For instance, the level at which call-back and job finding rates settle as duration grows large still informs the fraction of job-openings all workers are qualified for, $F(0)$. Likewise, the aggregate unemployment rate informs the contact rate between workers and job openings, $\lambda$.

We next argue that the parameters $\phi_{e}, \phi_{u}$, and $V$ are jointly pinned down by the shape of both the job finding and the callback rate against duration. To see why, note first that $\phi_{e}$ and $\phi_{u}$ determine the endogenous distribution of ability in the population, effectively replacing the parameters governing the exogenous Beta distribution in the baseline case. Thus, the argument linking the distribution of ability to our empirical targets made in the baseline carries over directly to this extended environment. However, we still need to

\footnotetext{
${ }^{48}$ The main culprit for the increased computational complexity is that the ergodic distribution of skills in the population endogenously depends on the hiring strategies of the employers.

${ }^{49}$ Of course, this does not imply that the estimation is under-identified since we target the job finding and callback rates at multiple durations.
} 
determine $V$. To see how $V$ is identified separately from the contact rate $\lambda$, note that $V$ has a limited impact on those workers whose chances of finding a job are insensitive to the queue length, that is those with low duration and high ability. In turn, $V$ matters sharply for those workers with large values $z(x, y, \tau)$. Thus, while $\lambda$ scales the contact rate for all workers, less congestion (higher $V$ ) disproportionately benefits those that tend to end up at the end of the queue. We thus argue that $V$, along with $\phi_{e}$ and $\phi_{u}$, can be disciplined by the information on relative job finding and callback rates we have previously used.

Our estimates for the parameters governing skill loss and skill growth are $\hat{\phi}_{u}=.0848$ and $\hat{\phi}_{e}=.0044$, respectively, giving rise to a steady state distribution of skill which has most mass at the corners, similar to the baseline. ${ }^{50}$ Our estimates which govern tightness in the labor market are $\hat{\lambda}=.6653$ and $\hat{V}=.0927$ while we estimate $F(0)=.6391 .{ }^{51}$

The model fits the empirical targets very tightly: It delivers an unemployment rate of $8.31 \%$ and completely captures the hazards in both the job finding and the callback rate as is evident in figure 8.

With the estimated model in hand, we employ the same counterfactual strategy to gauge the consequences of statistical discrimination. That is, we again contrast key moments with their counterpart in an environment with full information. ${ }^{52}$ Table 3 -corresponding to table 2 for our baseline model—offers our main results for the extended model.

It follows from the first three columns that the extended environment gives rise to a substantially larger impact of duration on job finding rates compared to our baseline case. Nevertheless, note that table 2 implies that moving to a full-information environment increases the monthly rate at which medium- and long term unemployed workers

\footnotetext{
${ }^{50}$ Our estimated human capital dynamics are very slow. The reason is that dynamic selection along with the ranking mechanism already generate large amounts of duration dependence both in callback and job finding rates, leaving little room for additional human capital dynamics. This is consistent with recent empirical work by Autor et al. (2015) and Schmieder et al. (2016) who find only small effects of additional time in unemployment on future productivity and wages. It is likewise consistent with the result in Kroft et al. (2013) that discrimination weakens in slack labor markets which would be hard to explain if skill decay was of first order force in the data.

${ }^{51}$ The latter may imply a surprisingly large fraction of job-openings that have few skill requirements. Note, however, that the context is the experimental setting in Kroft et al. (2013) which covers sales, customer service, administrative support, and clerical jobs (and constructs corresponding resumes). Thus, the finding that many jobs can be carried out by any applicant seems plausible.

${ }^{52}$ Under the counterfactual, the highest $x$ applicant gets hired, if qualified. This seems the most natural exercise and, in particular, compares most directly to the counterfactual in the baseline environment. However, there exists an alternative counterfactual where employers are banned from ranking on duration yet continue to interview in a sequential—but now random-fashion. Such an environment generates even less dynamic selection-because lower types get crowded out less frequently by high types-and hence is a counterfactual with even less duration dependence in the job finding rate. At the same time, it makes the overall hiring process more costly leading some firms to opt out of interviewing altogether which increases the incidence of long term unemployment.
} 
Figure 8: Extended Model Fit
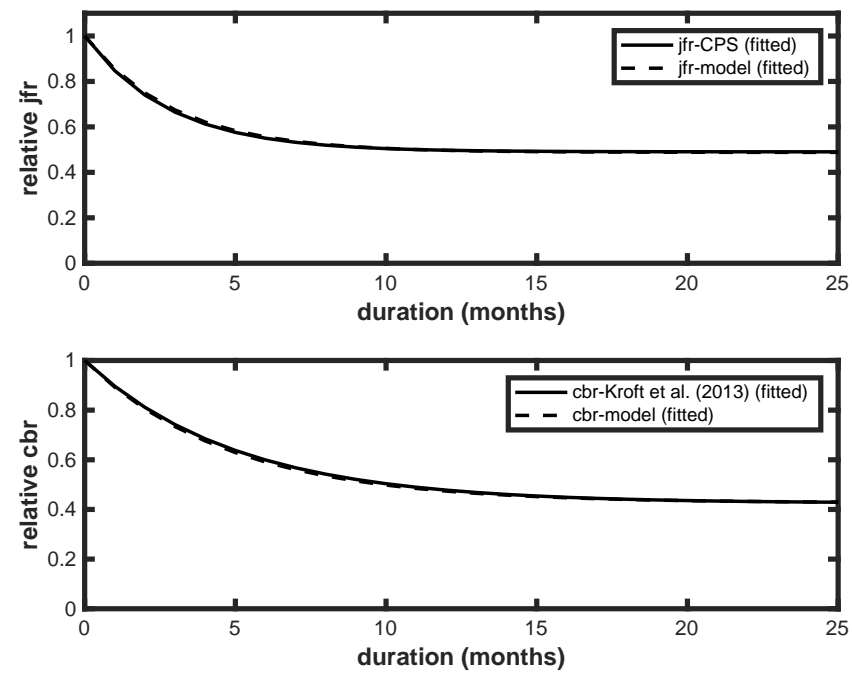

Notes: Average callback and job finding rates (normalized to duration $\tau=0$ ) as approximated by equation (13) in the extended model versus data reported in Kroft et al. (2015).

Table 3: The Consequences of Discrimination in the Extended Model

\begin{tabular}{lcccc} 
& $\mathrm{jfr}_{0-2}$ & $\mathrm{jfr}_{3-5}$ & $\mathrm{jfr}_{6+}$ & $\mathrm{ltu}$ \\
\hline baseline & 44.465 & 31.458 & 26.720 & 0.828 \\
\hline full information & 43.771 & 34.010 & 28.548 & 0.682 \\
\hline
\end{tabular}

Notes: All results are expressed in percent and correspond to steady states. First row: Baseline model with discrimination. Second row: Counterfactual with free interviews. First column: Average monthly job finding rate of workers with unemployment duration $\tau=0-2$ months. Second Column: $\tau=3-5$ months. Third Column: $\tau \geq 6$ months. Fourth column: Fraction of the population in long term unemployment, that is with $\tau \geq 6$. 
exit unemployment by $7-8 \%$. While this constitutes a more sizable reduction in the exit rate from unemployment attributable to statistical discrimination, it still contrasts sharply with the increase in the callback rate induced by the counterfactual: the long term unemployed experience an approximately two-fold increase in their evaluation opportunities for a job-opening, as is evident from the lower panel in figure 8. This implies that the increase in the interview rate for the medium and long term unemployed exceeds the associated increase in the job finding rate by more than an order of magnitude.

Importantly, and as opposed to the benchmark without multiple applications, this response comes at the cost of the short-term unemployed who, on average, benefit from the ranking practice and hence see a decline of their job finding rates by almost $2 \%{ }^{53}$ Taken together, the mild increases in the monthly job finding rates accumulate to a decline in the incidence of long term unemployment from $.83 \%$ to $.68 \%$. Thus, under the extended model, a modest fraction of long term unemployment can indeed be attributed to statistical discrimination as detected by the experimental evidence.

To sum up, allowing for human capital decay during unemployment and ranking due to coordination frictions amplifies the role of statistical discrimination in callbacks for duration dependence in the job finding rate and long term unemployment. Nonetheless, few of the interviews the long term unemployed lose to duration constitute jobs lost to duration: Eliminating discrimination increases monthly callbacks by around $100 \%$ for those who are a long time out of work; yet their job finding rates increase by only around $7-8 \%$. We thus conclude that, even in the extended environment and under a conservative empirical strategy, statistical discrimination in callbacks is largely a response to dynamic composition changes and much less a cause of duration dependence in the job finding rate or a cause of long term unemployment.

\section{Conclusion}

In this paper we develop an equilibrium search model in which employers endogenously discriminate against unemployment duration at the interview, or callback stage. The quantitative model closely captures empirical evidence on statistical discrimination in callbacks as documented in Kroft et al. (2013). We use the model to quantify the conse-

\footnotetext{
${ }^{53}$ For this reason, we do not include the decomposition exercise from section 4.2 here as it is ill-suited for the extended model: In particular, ranking according to unemployment duration puts the short term unemployed in an advantage which artificially inflates their job finding rate. That is, not only do the long term unemployed suffer, the short term unemployed benefit from discrimination. As a consequence, tracing out the purely compositional implications based on fixed $\tau=0$ job finding rates leads to misleading conclusions about the role of discrimination in generating duration dependence in the job finding rate.
} 
quences of such employer behavior for structural duration dependence in the job finding rate and the incidence of long term unemployment in the aggregate labor market. Our findings suggest that most interviews diagnosed as lost to duration in an audit study do not actually constitute lost jobs. As a consequence, employer discrimination in callbacks is largely a response to dynamic selection rather than a major force causing structural declines in the unemployment exit rate. We point to the key tradeoff driving these findings: If the foregone gains to the employer from filling a job far exceed the cost of pursuing an application, then false negatives in interviews - episodes where employers do not call back a qualified candidate - will be endogenously rare.

Our paper provides the first attempt to link the evidence from the experimental literature regarding discrimination in callbacks to real outcomes in the labor market in a quantitatively serious fashion. The approach builds on a structural model which lends itself closely to the experimental setting, uses the experimental evidence to discipline the structure, and finally uses the structure to draw inference from the experimental data. In sum, the experimental literature helps to inform our structural model and the same model helps to interpret the experimental evidence. We believe that such an approach can be fruitfully used to map novel experimental evidence to outcomes of interest in many other settings.

\section{References}

Ahn, Hie Joo and James D. Hamilton, "Heterogeneity and Unemployment Dynamics," December 2017.

Albrecht, James and Susan Vroman, "A Matching Model with Endogenous Skill Requirements," International Economic Review, 2002, 43 (1), pp. 283-305.

Altonji, Joseph G., Lisa B. Kahn, and Jamin D. Speer, "Cashier or Consultant? Entry Labor Market Conditions, Field of Study, and Career Success," Journal of Labor Economics, 2016, 34 (S1), S361-S401.

Alvarez, Fernando, Katarina Borovickova, and Robert Shimer, “Decomposing Duration Dependence in a Stopping Time Model," 2016.

Arrow, Kenneth, "The theory of discrimination," 1973.

Autor, David H., Nicole Maestas, Kathleen J. Mullen, and Alexander Strand, "Does Delay Cause Decay? The Effect of Administrative Decision Time on the Labor Force Participation and Earnings of Disability Applicants," Working Paper 20840, National Bureau of Economic Research January 2015. 
Barnichon, Regis and Andrew Figura, "Labor Market Heterogeneity and the Aggregate Matching Function," American Economic Journal: Macroeconomics, October 2015, 7 (4), $222-49$.

Barron, John and John Bishop, "Extensive Search, Intensive Search, and Hiring Costs: New Evidence on Employer Hiring Activity," Economic Inquiry, 1985, 23 (3), 363-82.

Barron, John M, Mark C Berger, and Dan A Black, "Employer Search, Training, and Vacancy Duration," Economic Inquiry, January 1997, 35 (1), 167-92.

Blanchard, Olivier Jean and Peter A Diamond, "Ranking, Unemployment Duration, and Wages," Review of Economic Studies, July 1994, 61 (3), 417-34.

Bos, Marieke, Emily Breza, and Andres Liberman, "The Labor Market Effects of Credit Market Information," Working Paper 22436, National Bureau of Economic Research July 2016.

Chernozhukov, Victor and Han Hong, "An MCMC approach to classical estimation," Journal of Econometrics, 2003, 115 (2), 293 - 346.

Coate, Stephen and Glenn C Loury, "Will Affirmative-Action Policies Eliminate Negative Stereotypes?," American Economic Review, December 1993, 83 (5), 1220-40.

Code-32-162, "Washington D.C.. Prohibition on Discrimination against the Unemployed. Code Â§ 32-1362 (2012)," 2012.

Davis, Steven J and Till von Wachter, "Recessions and the Costs of Job Loss.," Brookings Papers on Economic Activity, 2011, (2).

den Berg, Gerard J. Van, "Duration models: specification, identification and multiple durations," in J.J. Heckman and E.E. Leamer, eds., Handbook of Econometrics, Vol. 5 of Handbook of Econometrics, Elsevier, January 2001, chapter 55, pp. 3381-3460.

Doppelt, Ross, "The Hazards of Unemployment," 2016.

Duygan-Bump, Burcu, Alexey Levkov, and Judit Montoriol-Garriga, "Financing constraints and unemployment: Evidence from the Great Recession," Journal of Monetary Economics, 2015, 75, 89- 105.

Eriksson, Stefan and Dan-Olof Rooth, “Do Employers Use Unemployment as a Sorting Criterion When Hiring? Evidence from a Field Experiment," American Economic Review, 2014, 104 (3), 1014-39.

Fallick, Bruce C. and Charles A. Fleischman, "Employer-to-employer flows in the U.S. labor market: the complete picture of gross worker flows," 2004.

Farber, Henry S., Dan Silverman, and Till von Wachter, "Determinants of Callbacks to Job Applications: An Audit Study," American Economic Review, May 2016, 106 (5), 31418. 
Fernandez-Blanco, Javier and Edgar Preugschat, "On the Effects of Ranking by Unemployment Duration," 2017.

Gertler, Mark and Antonella Trigari, "Unemployment Fluctuations with Staggered Nash Wage Bargaining," Journal of Political Economy, 2009, 117 (1), 38-86.

Ghayad, Rand, “The Jobless Trap," 2013.

Hagedorn, Marcus and Iourii Manovskii, "The Cyclical Behavior of Equilibrium Unemployment and Vacancies Revisited," American Economic Review, September 2008, 98 (4), 1692-1706.

Haltiwanger, John, Henry Hyatt, and Erika McEntarfer, "Cyclical Reallocation of Workers Across Employers by Firm Size and Firm Wage," Working Paper 21235, National Bureau of Economic Research June 2015.

Heckman, James and Burton Singer, "A Method for Minimizing the Impact of Distributional Assumptions in Econometric Models for Duration Data," Econometrica, March 1984, 52 (2), 271-320.

Heckman, James J., “Detecting Discrimination," Journal of Economic Perspectives, 1998, 12 (2), 101-116.

Jarosch, Gregor, "Searching for Job Security and the Consequences of Job Loss," 2015.

Kekre, Rohan, “Unemployment Insurance In Macroeconomic Stabilization," 2017.

Kroft, Kory, Fabian Lange, and Matthew J. Notowidigdo, "Duration Dependence and Labor Market Conditions: Evidence from a Field Experiment," The Quarterly Journal of Economics, 2013, 128 (3), 1123-1167.

- , _ , , , and Lawrence F. Katz, "Long-Term Unemployment and the Great Recession: The Role of Composition, Duration Dependence and Non-Participation," Journal of Labor Economics, 2015.

Krueger, Alan B. and Andreas I. Mueller, "A Contribution to the Empirics of Reservation Wages," American Economic Journal: Economic Policy, February 2016, 8 (1), 142-179.

Lamadon, Thibaut, "Productivity Shocks, Long-Term Contracts and Earnings Dynamics," January 2016.

Law-2013-014, "Committee on Civil Rights. Prohibiting discrimination based on an individualâs unemployment. Law number 2013/014.," 2013.

Lise, Jeremy and Jean-Marc Robin, "The Macrodynamics of Sorting between Workers and Firms," American Economic Review, April 2017, 107 (4), 1104-35.

_ , Costas Meghir, and Jean-Marc Robin, "Matching, sorting and wages," Review of Economic Dynamics, 2016, 19 (Supplement C), 63 - 87.

Ljungqvist, Lars and Thomas J. Sargent, "The European Unemployment Dilemma," Journal of Political Economy, 1998, 106 (3), 514-550. 
Lockwood, Ben, "Information Externalities in the Labour Market and the Duration of Unemployment," Review of Economic Studies, July 1991, 58 (4), 733-53.

Meghir, Costas and Luigi Pistaferri, "Income Variance Dynamics and Heterogeneity," Econometrica, 2004, 72 (1), 1-32.

Oberholzer-Gee, Felix, "Nonemployment stigma as rational herding: A field experiment," Journal of Economic Behavior \& Organization, January 2008, 65 (1), 30-40.

Public-Law-2011, “Public Law 2011. , Chapter 40, N.J.S.A. 34:8B-1 - 34:8B-2,” 2011.

Schmieder, Johannes F., Till von Wachter, and Stefan Bender, "The Effect of Unemployment Benefits and Nonemployment Durations on Wages," American Economic Review, March 2016, 106 (3), 739-77.

Senate-Bill-1548, “Job Posting Restrictions. OR S 1548.," 2012.

Sharone, Ofer, Rand Ghayad, Gokce Basbug, Alex Vasquez, and Michelle Rosin, "Supporting Experienced LTU Professionals," in Carl Van Horn, Tammy Edwards, and Todd Greene, eds., Transforming U.S. Workforce Development Policies for the 21st Century, W.E. Upjohn Institute for Employment Research, 2015.

Shimer, Robert, "The Cyclical Behavior of Equilibrium Unemployment and Vacancies," American Economic Review, March 2005, 95 (1), 25-49.

- , "The Assignment of Workers to Jobs in an Economy with Coordination Frictions," Journal of Political Economy, October 2005, 113 (5), 996-1025.

Silva, Jose Ignacio and Manuel Toledo, "Labor turnover cost and the cyclical behavior of vacancies and unemployment," Macroeconomic Dynamics, 5 2009, 13, 76-96.

Torgovitsky, Alexander, "Nonparametric Inference on State Dependence with Applications to Employment Dynamics," Technical Report 2016.

UADA, "The Unemployed Anti-Discrimination Act of 2012" , available at: https: //ohr.dc.gov/sites/default/files/dc/sites/ohr/publication/attachments/ UADA-SignedAct.pdf (accessed 12/09/2017), 2012.

USDOL, "Training and Employment Notice," October 2014.

Vishwanath, Tara, "Job Search, Stigma Effect, and Escape Rate from Unemployment," Journal of Labor Economics, October 1989, 7 (4), 487-502.

White-House, "Addressing the Negative Cycle of Long Term Unemployment," January 2014.

_ , "Enhancing Safeguards to Prevent the Undue Denial of Federal Employment Opportunities to the Unemployed and Those Facing Financial Difficulty Through no Fault of Their Own.," January 2014. 


\section{A Proof of Proposition 1}

That firms use a threshold rule in their hiring decision follows immediately from equations (1) and (5).

To prove the additional parts of the proposition, we first establish two helpful intermediate results.

Lemma 1. Conditional on unemployment duration $\tau \geq 0$, the job finding probability is nondecreasing in $x$.

To see this, note that equation (6) implies that the callback rate is independent of $x$ and solely depends on $\tau$. Since, by assumption, $p$ is nondecreasing in $x$, it follows that if $p\left(x_{2}, y\right) \geq b$ and $x_{1}>x_{2}$ then $p\left(x_{1}, y\right) \geq b$. Thus any application that leads to job for worker $x_{2}$ also leads to a job for worker $x_{1}$ and it thus follows that the job finding probability, given duration $\tau$, is non-decreasing in $x$.

Lemma 2. All firms $y \in Y$ call back newly unemployed workers with duration $\tau=0$.

In (7) we assume that all firms call back when faced with the population distribution of worker types. To show that this carries over to the distribution of newly unemployed, denote by $\bar{f}(x)$ the rate at which type $x$ workers exit unemployment, averaged across all durations. As a consequence of lemma $1, \bar{f}(x)$ is weakly increasing in $x$. A standard inflow-outflow balance implies that steady-state type-specific employment rate is given by $e(x)=\frac{\bar{f}(x)}{\delta_{L}+\bar{f}(x)}$. Since $\bar{f}(x)$ is weakly increasing it follows that the employment rate $e(x)$ is weakly increasing in $x$.

The probability of meeting a worker with $x$ exceeding some threshold $\bar{x}_{y}$ in the population is given by $\int_{\bar{x}_{y}} l\left(x^{\prime}\right) d x^{\prime}$, while the probability of meeting a worker exceeding the same threshold among those employed is given by $\frac{1}{\int e\left(x^{\prime}\right) l\left(x^{\prime}\right) d x} \int_{\bar{x}_{y}} e\left(x^{\prime}\right) l\left(x^{\prime}\right) d x^{\prime}$. The latter is weakly larger for all thresholds $\bar{x}_{y}>\underline{\mathrm{x}}$ since the type-specific employment rates are weakly increasing. As a consequence, the distribution of $x$ among the employed weakly first-order stochastically dominates the one of the population. Finally, since the separation rate is independent of types, the distribution of $x$ among the newly unemployed, $\mu(x \mid \tau=0)$, is identical to that of the employed. Since equation (7) holds for all firms $y \in Y$, we thus have that

$$
\int \max \left\{J\left(x^{\prime}, y\right), 0\right\} \mu\left(x^{\prime} \mid \tau=0\right) d x^{\prime}>0 \quad \forall y .
$$

That is, all firms call back when receiving an application from a newly unemployed worker. 
To prove proposition 1, we proceed by contradiction. Without loss of generality, order firms according to their minimum skill requirement $\underline{x}_{y}$ as defined in the production function (1). Assume then that the call-back rate never falls, that is all firms call back at all durations implying that the economy does not feature discrimination. This immediately implies that the job finding rate is independent of duration for all workers $x$.

Now consider the firm $y$ with the highest threshold $\underline{x}_{y}>\underline{x}$ such that $1-F(y)>0$. That such a firms exist is guaranteed by assumption (8). That the firm calls back is guaranteed by lemma 2. Since workers with $x \geq \underline{\mathrm{x}}_{y}$ then have strictly higher job finding rates than all other workers in the labor market and $l(x)$ has full support, we have that $\lim _{\tau \rightarrow \infty} \int_{\underline{\mathbf{x}}_{y}} \mu\left(x^{\prime} \mid \tau\right) d x=0$. As a consequence, inequality (6) cannot be satisfied for the firm with the highest threshold as $\tau$ grows large. ${ }^{54}$ This establishes a contradiction implying that it cannot be that all firms call back at all durations.

To show that the callback rate does not increase for any $\tau$, we verify that firms follow cutoff rules with respect to duration. Since we have shown that the job finding rate is weakly increasing in $x$ at all durations $\tau$, the distribution of types $x$ at $\tau$ weakly first order stochastically dominates the one at $\tau+1$. Equations (1), (4), and (6) then imply that the expected surplus from interviewing a duration $\tau$ worker must weakly exceed that from interviewing a duration $\tau+1$ worker. Hence, if a firm does not call back workers with duration $\tau$ it never calls back any workers with higher duration, establishing that firms' interview decisions follow a cutoff rule. Thus, the call-back rate cannot be flat and cannot ever increase, which implies the equilibrium features discrimination as defined in 1.

\section{B Job finding Rates, Separation Rates, and Duration De- pendence in the CPS}

To construct estimates of monthly labor market flows, we match individuals between months $t$ and $t+1$ in the basic monthly CPS files, where we can observe their employment status and their unemployment duration if currently unemployed as well as various demographic characteristics. After dropping individuals with missing labor market status in either month $t$ or $t+1$ and restricting the sample to individuals between the ages of 16 and 64, we characterize an individual as having found a job between months $t$ and $t+1$ if they are employed in month $t+1$ and unemployed in month $t$. Similarly, to calculate the monthly job-to-job transition probability in the CPS, we follow the procedure outlined in Fallick and Fleischman (2004) who use the dependent interviewing methods

\footnotetext{
${ }^{54}$ It is straightforward to verify that this is true for any firm with threshold $\underline{x}_{y}>\underline{\mathbf{x}}$.
} 
which started in 1994 to identify workers who remain employed in month $t+1$, but for a different employer than during month $t$. We then measure the job-to-job transition probability as the share of employed workers in month $t$ that are employed in $t+1$ at a different employer. Finally, we measure the separation probability into unemployment as the share of individuals who are employed in month $t$ and not employed in month $t+1$.

To estimate the unconditional duration dependence in the job finding rate which we plot in Figure (1), we pool all the data from the monthly files for the relevant time period and regress job finding dummies on dummies for unemployment duration and year and month controls, and plot the coefficients we estimate on duration (normalized by the mean job finding rate for duration $\tau=0$ ). To get conditional duration dependence in the job finding rate, we add in controls to the same regression for, age, race education and sex, as well as interactions between these variables and sex.

\section{Details of the Extended Model}

\section{Deriving $z(x, y, \tau)$}

Assume a firm has thus far interviewed at least one candidate and the ability of the most productive applicant is again denoted by $\hat{x}$. The firm then needs to decide whether it wants to interview an additional applicant, guided by equation (20). We let $\bar{\tau}_{y}(\hat{x})$ denote the maximum duration of the next applicant in the ranking such that the firm proceeds to grant another interview. That is, $\bar{\tau}_{y}(\hat{x})$ is the highest duration $\tau$ such that equation (20) holds. ${ }^{55}$

Assume a worker with duration $\tau$ and ability $x$ applies to firm $y$, with $y \leq x$ and $\tau \leq \bar{\tau}_{y}$, such that the worker is qualified and the firm is, in principle, willing to call back. The worker will not get the job if the firm receives at least one application from a worker $\left(\tau^{\prime}, x^{\prime}\right)$ such that at least one of the following three cases holds

a) $\tau^{\prime} \leq \tau$ and $\bar{\tau}_{y}\left(x^{\prime}\right)<\tau$ : in this case the other applicant gets interviewed first due to ranking. Her ability is high enough such that the firm stops interviewing before getting to applicants with duration $\tau .{ }^{56}$

b) $\tau^{\prime} \leq \tau$ and $\bar{\tau}_{y}\left(x^{\prime}\right) \geq \tau$ but $x^{\prime} \geq x$ : in this case the other applicant gets interviewed first due to ranking. Her ability is low enough such that the firm continuous to

\footnotetext{
${ }^{55}$ Of course, equation (20) may not hold for any weakly positive $\tau$.

${ }^{56}$ Whenever the inequalities are weak we assume that the firm randomizes. As a consequence, applications from competitors with identical $x$ or $\tau$ are down-weighted by $50 \%$ in the expression for $z(x, y, \tau)$ below.
} 
interview applicants with duration $\tau$ but $x^{\prime}$ is still preferred over $x$.

c) $\tau \leq \tau^{\prime} \leq \bar{\tau}_{y}(x)$ and $x^{\prime} \geq x$ : in this case worker $x$ gets interviewed but the firm proceeds to interview worker $\tau^{\prime}$ who turns out to be (at least weakly) more productive.

Let $\mu(x, \tau)$ denote the joint distribution of skill and duration among the unemployed types. The fraction of unemployed workers who crowd out an $(x, \tau)$ worker at firm $y$ is given by

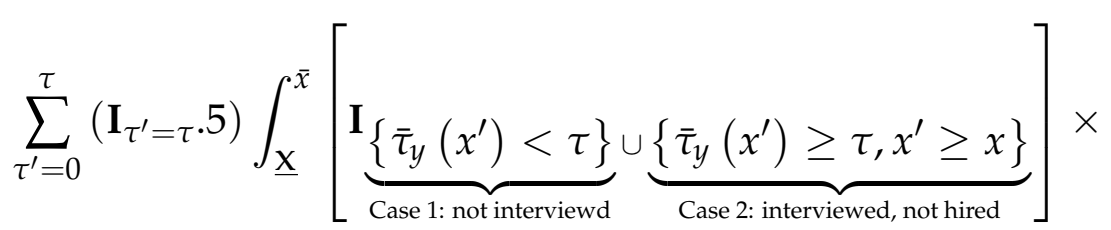

$$
\begin{aligned}
& \underbrace{\left(1-\left(\mathbf{I}_{\left\{\bar{\tau}_{y}\left(x^{\prime}\right) \geq \tau, x^{\prime}=x\right\}} .5\right)\right)}_{\text {Correction for indifference }} \mu\left(x^{\prime} \mid \tau^{\prime}\right) d x^{\prime} \\
& +\sum_{\tau^{\prime}=\tau}^{\bar{y}_{y}(x)}\left(\mathbf{I}_{\tau^{\prime}=\tau} .5\right) \int_{\underline{\mathbf{X}}}^{\bar{x}} \underbrace{\mathbf{I}_{x^{\prime} \geq x}}_{\text {Case 3: } \mathbf{x}^{\prime} \text { preferred }}\left(1-\left(\mathbf{I}_{x^{\prime}=x} \cdot 5\right)\right) \mu\left(x^{\prime} \mid \tau^{\prime}\right) d x^{\prime}
\end{aligned}
$$

Since $z(x, y, \tau)$ is defined as the measure of the corresponding type of workers this expression needs to be multiplied with the aggregate unemployment rate to obtain $z(x, y, \tau)$.

\section{Worker Values}

We write the value functions for the general case where the wage depends on both firm and worker type and the worker's duration at unemployment exit, $w(x, y, \tau)$. The value of employment at firm $y$ is then

$$
W(x, y, \tau)=w(x, y, \tau)+\beta \mathbf{E}_{x^{\prime} \mid x, e}\left(W\left(x^{\prime}, y, \tau\right)+\delta_{L}\left(U\left(x^{\prime}, 0\right)-W\left(x^{\prime}, y, \tau\right)\right)\right)
$$

where the expectation operator accounts for the fact that skills evolve according to the workers employment state, $e$ in this case. Next, we can write the value of unemployment to a type worker who is unemployed for $\tau$ months as as

$$
\begin{aligned}
U(x, \tau) & =b+\beta \mathbf{E}_{x^{\prime} \mid x, u}\left(U\left(x^{\prime}, \tau+1\right)+\right. \\
& \left.\left.+\lambda \int_{y \in I(\tau) \cap H(x)} \exp \left(-\lambda \frac{z(x, y, \tau)}{V}\right)\left(W\left(x^{\prime}, y, \tau+1\right)-U\left(x^{\prime}, \tau+1\right)\right) d F(y)\right)\right)
\end{aligned}
$$


where the expectation operator accounts for the fact that skills evolve differently in unemployment.

\section{Steady State Stocks}

For expositional purposes we discretize ability $x$ which is also the case we numerically implement. We do so on a grid of size $n$ and assume that workers have some skill $x \in\left\{x_{1}, \ldots, x_{n}\right\}$. We also impose the particular transition matrix for skills we empirically implement. Then, while a worker is unemployed, her type decreases to $x_{\max \{1, i-1\}}$ with probability $\phi_{u}$. Similarly, during employment, her type increases from $x_{i}$ to $x_{\min \left\{x_{n}, x_{i+1}\right\}}$ with probability $\phi_{e}$. Denote by $e\left(x_{i}\right)$ the steady state measure of employed types $x_{i}$. The measure of types $x_{i}$ unemployed with duration $\tau$ satisfies

$$
u\left(x_{i}, \tau\right)= \begin{cases}\delta_{L}\left[e\left(x_{i}\right)\left(1-\phi_{u}\right)+e\left(x_{\min \{i+1, n\}}\right) \phi_{u}\right] \\ +\delta_{L}\left[\mathbf{I}_{\{i=1\}} e\left(x_{i}\right) \phi_{u}-\mathbf{I}_{\{i=n\}} e\left(x_{i}\right) \phi_{u}\right] \\ u\left(x_{i}, \tau-1\right)\left(1-f\left(x_{i}, \tau-1\right)\right)\left(1-\phi_{u}\right) & \text { if } \tau=0 \\ +u\left(x_{\min \{i+1, n\}}, \tau-1\right)\left(1-f\left(x_{\min \{i+1, n\}}, \tau-1\right)\right) \phi_{u} & \\ +\mathbf{I}_{\{i=1\}} u\left(x_{i}, \tau-1\right)\left(1-f\left(x_{i}, \tau-1\right)\right) \phi_{u} & \\ -\mathbf{I}_{\{i=n\}} u\left(x_{i}, \tau-1\right)\left(1-f\left(x_{i}, \tau-1\right)\right) \phi_{u} & \text { if } \tau>0 .\end{cases}
$$

In turn,

$$
\begin{aligned}
e\left(x_{i}\right)= & \left(1-\delta_{L}\right)\left\{e\left(x_{i}\right)\left(1-\phi_{e}\right)+e\left(x_{\max \{i-1,1\}}\right) \phi_{e}\right\} \\
& +\sum_{\tau=0}^{\infty} u\left(x_{i}, \tau\right)\left\{u\left(x_{i}, \tau\right) f\left(x_{i}, \tau\right)\left(1-\phi_{e}\right)+u\left(x_{\max \{i-1,1\}}, \tau\right) f\left(x_{\max \{i-1,1\}}, \tau\right) \phi_{e}\right\} \\
& -\mathbf{I}_{\{i=1\}}\left\{e\left(x_{i}\right) \phi_{e}+\sum_{\tau} u\left(x_{i}, \tau\right) f\left(x_{i}, \tau\right) \phi_{e}\right\} \\
& +\mathbf{I}_{\{i=n\}}\left\{e\left(x_{i}\right) \phi_{e}+\sum_{\tau} u\left(x_{i}, \tau\right) f\left(x_{i}, \tau\right) \phi_{e}\right\}
\end{aligned}
$$

while the adding-up constraint is

$$
\sum_{i=1}^{n} e\left(x_{i}\right)+\sum_{i=1}^{n} \sum_{\tau=0}^{\infty} u\left(x_{i}, \tau\right)=1
$$




\section{Equilibrium}

A steady state equilibrium of the economy with multiple applications and human capital depreciation is a quadruple $\{H, I, u, e\}$ where the hiring set $H$ satisfies (5), the interview set $I$ satisfies (6), and the allocation $\{u, e\}$ satisfies (23)-(25). 